\title{
Observations of prolific transient luminous event production above a mesoscale convective system in Argentina during the Sprite2006 Campaign in Brazil
}

\author{
F. T. São Sabbas, ${ }^{1}$ M. J. Taylor, ${ }^{2}$ P.-D. Pautet, ${ }^{2}$ M. Bailey, ${ }^{2}$ S. Cummer, ${ }^{3}$ \\ R. R. Azambuja, ${ }^{1}$ J. P. C. Santiago, ${ }^{1}$ J. N. Thomas, ${ }^{4,5}$ O. Pinto, ${ }^{1}$ N. N. Solorzano, ${ }^{4}$ \\ N. J. Schuch, ${ }^{6}$ S. R. Freitas, ${ }^{1}$ N. J. Ferreira, ${ }^{1}$ and J. C. Conforte $^{1}$ \\ Received 1 September 2009; revised 29 March 2010; accepted 28 May 2010; published 2 November 2010.
}

[1] On the night of 22-23 February 2006, 444 transient luminous events (TLEs), 86\% sprites, were observed above a prolific mesoscale convective system (MCS) over Argentina, as part of the third sprite campaign in Brazil. GOES infrared (IR) cloud top temperatures $\left(T_{c}\right)$ and Tropical Rainfall Measuring Mission (TRMM) radar (PR) and microwave (TMI) data were used to investigate the MCS convective characteristics and their relationship with World Wide Location Network (WWLLN) detected cloud-to-ground (CG) lightning and TLE activity. The MCS had a minimum lifetime of 20 hours, 8.5 as a MCS, a maximum extent of $\sim 430,000 \mathrm{~km}^{2}$, and gusty winds of $\sim 39-50 \mathrm{~km} / \mathrm{h}$. It had several distinctive characteristics: exceptionally high TLE rate, multicellular structure with 19 distinguishable convective regions, and cloud tops temperatures $\left(\mathrm{T}_{\mathrm{c}}\right) \sim 10-20^{\circ} \mathrm{C}$ higher than regular TLEproducing MCSs over the central USA and South America. Most TLEs occurred above "individual stratiform regions", where $\mathrm{T}_{\mathrm{c}}$ varied from $-45^{\circ} \mathrm{C}$ to $-53{ }^{\circ} \mathrm{C}$ from the beginning to the end of the night, surrounding the areas of strong convections, with convective cores at $\mathrm{T}_{\mathrm{c}}-59{ }^{\circ} \mathrm{C}$ to $-74{ }^{\circ} \mathrm{C}$, which did not extend up to or overshoot the tropopause, estimated at $-75^{\circ} \mathrm{C}(\sim 17.1 \mathrm{~km})$ as normally observed for TLE-producing MCS in these regions. The moderated convection is contrary to the expectation that large charge production is accompanied by vigorous updrafts within deep convection that give rise to cold cloud overshooting tops, thus prompting a detailed study of this prolific TLE-producing thunderstorm. On the basis of a charge moment change threshold of $350 \mathrm{Ckm}$ and estimated $5 \mathrm{~km}$ charge removal altitude, a lower threshold of $\sim 4,300 \mathrm{C} / \mathrm{h}$ was estimated for the hourly charge transfer rate necessary for the observed sprite production (383 events), which is twice the rate for an average TLE-producing MCS (70 events), also estimated. TMI/TRMM data for the storm at early development showed a low brightness temperature of $84 \mathrm{~K}$, indicative of significant ice content, which is important for cloud electrification processes. We suggest that the unusually high incidence of TLEs in this moderately convective MCS may be related to other local geophysical phenomena such as a large tropospheric aerosol concentration due to smoke from forest fires. Satellite fire count data showed that there were $\sim 200$ fires between 20 and 22 February immediately north of the MCS initiation region and a transport simulation with the Coupled Aerosol-Tracer Transport model from the Brazilian developments on Regional Atmospheric Modeling System (CATT/BRAMS) model showed a large $\mathrm{PM}_{2.5}$ aerosol concentration, $10,000 \mu \mathrm{g} / \mathrm{m}^{2}$ (column integrated), at the region where the MCS developed. The aerosols present in the smoke may have been a source of ice nuclei affecting the production of ice particles that get positively charged, accounting for the charge transfer rate necessary to originate the observed TLE production.

Citation: São Sabbas, F. T., et al. (2010), Observations of prolific transient luminous event production above a mesoscale convective system in Argentina during the Sprite2006 Campaign in Brazil, J. Geophys. Res., 115, A00E58, doi:10.1029/2009JA014857.

\footnotetext{
${ }^{1}$ Instituto Nacional de Pesquisas Espaciais, São José dos Campos, São Paulo, Brazil.

${ }^{2}$ Center for Atmospheric and Space Sciences, Utah State University, Logan, Utah, USA.

Copyright 2010 by the American Geophysical Union. 0148-0227/10/2009JA014857
}

\footnotetext{
${ }^{3}$ Electrical and Computer Engineering Department, Duke University, Durham, North Carolina, USA.

${ }^{4}$ Department of Electrical and Computer Engineering, Digipen Institute of Technology, Redmond, Washington, USA.

${ }^{5}$ Also at University of Washington, Seattle, Washington, USA.

${ }^{6}$ Southern Regional Space Research Center, CRS, INPE-MCT, Santa Maria, Rio Grande do Sul, Brazil.
} 


\section{Introduction}

[2] Transient luminous events (TLEs) is the generic term adopted by researchers to refer to sprites, ELVEs, halos, sprite halos, blue jets, gigantic jets, and other transient upper atmospheric optical phenomena associated with lightning. They were serendipitously discovered in 1989 when sprites were documented for the first time [Franz et al., 1990]. These observations turned out to be only one of a large class of phenomena and were initially thought to be cloud-toionosphere or cloud-to-stratosphere lightning discharges. However, to avoid ascribing physical properties to the events before they were actually known, Sentman et al. [1995] suggested using an attribute-free name for the events and proposed the neutral term sprite (Figure 1).

[3] Sprites are short-lived (a few ms to $\sim 100$ s of ms) with optical emissions predominantly in the red $\mathrm{N}_{2} 1 \mathrm{PG}$ bands [Hampton at al., 1996]. Initial brightness estimates indicated that they were of low luminosity ( 100 kR to $\sim 10 \mathrm{MR})$ on the basis of video observations, but more recent observations using high-speed (10,000 frames per second) cameras showed that the brightness of the streamer heads in the sprites can exceed 1 GR [Stenbaek-Nielsen et al., 2000]. They span vertical altitudes of $\sim 30 \mathrm{~km}$ to $\sim 100 \mathrm{~km}$ and typically have lateral dimensions of a few tens of meters to $\sim 40 \mathrm{~km}$ [Gerken et al., 2000; Stenbaek-Nielsen et al., 2000]. Sprites are associated with cloud-to-ground (CG) lightning discharges, primarily of positive polarity [Boccipio et al., 1995; Lyons, 1996; São Sabbas et al., 2003]. Currently, the most accepted mechanism for their production is electron impact ionization and excitation, in which ambient electrons in the mesosphere gain enough energy from the transient quasielectrostatic field from an underlying lightning discharge to ionize the air, creating breakdown, and produce air fluorescence primarily from $\mathrm{N}_{2}$ [Pasko et al., 1997; São Sabbas, 2003]. Recent models focus on the description of the mesospheric plasma streamers that compose the sprites and are expected to develop at the locations where breakdown occurs [Pasko et al., 1998; Raizer et al., 1998; Liu and Pasko, 2004; Luque and Ebert, 2009].

[4] Sprites can be preceded (or accompanied) by halos, which are horizontal disk-shaped transient optical emissions. Triangulation measurements by Wescott et al. [2001] determined that halos occur centered at an average altitude of $\sim 78 \mathrm{~km}$ and exhibit a Gaussian 1/e thickness of $\sim 4 \mathrm{~km}$ and $1 / e$ diameter of $\sim 66 \mathrm{~km}$, whereas photometric studies using a single site measurement yielded an estimated center altitude of $\sim 87 \mathrm{~km}$ [Miyasato et al., 2002]. Halos, which have a similar initiation mechanism to sprites and appear red in color, can also occur as isolated events. Before halos were identified as a unique type of TLE [Wescott et al., 2001; Barrington-Leigh et al., 2001], they were often (incorrectly) interpreted as ELVEs in image data. ELVEs, however, are characterized by rapid lateral expansion of ringlike emissions that occur at higher altitudes at the base of the nighttime ionosphere $(\sim 100 \mathrm{~km}$ altitude) and are produced by the electromagnetic pulse from cloud-to-ground discharges of either polarity [Inan et al., 1997; Chen et al., 2008]. Despite their similarity in shape, ELVEs are usually much more horizontally extended than halos and can reach a few hundred kilometers in diameter. Their optical lifetimes are on the order of a few microseconds. The apparent luminosity of ELVEs is
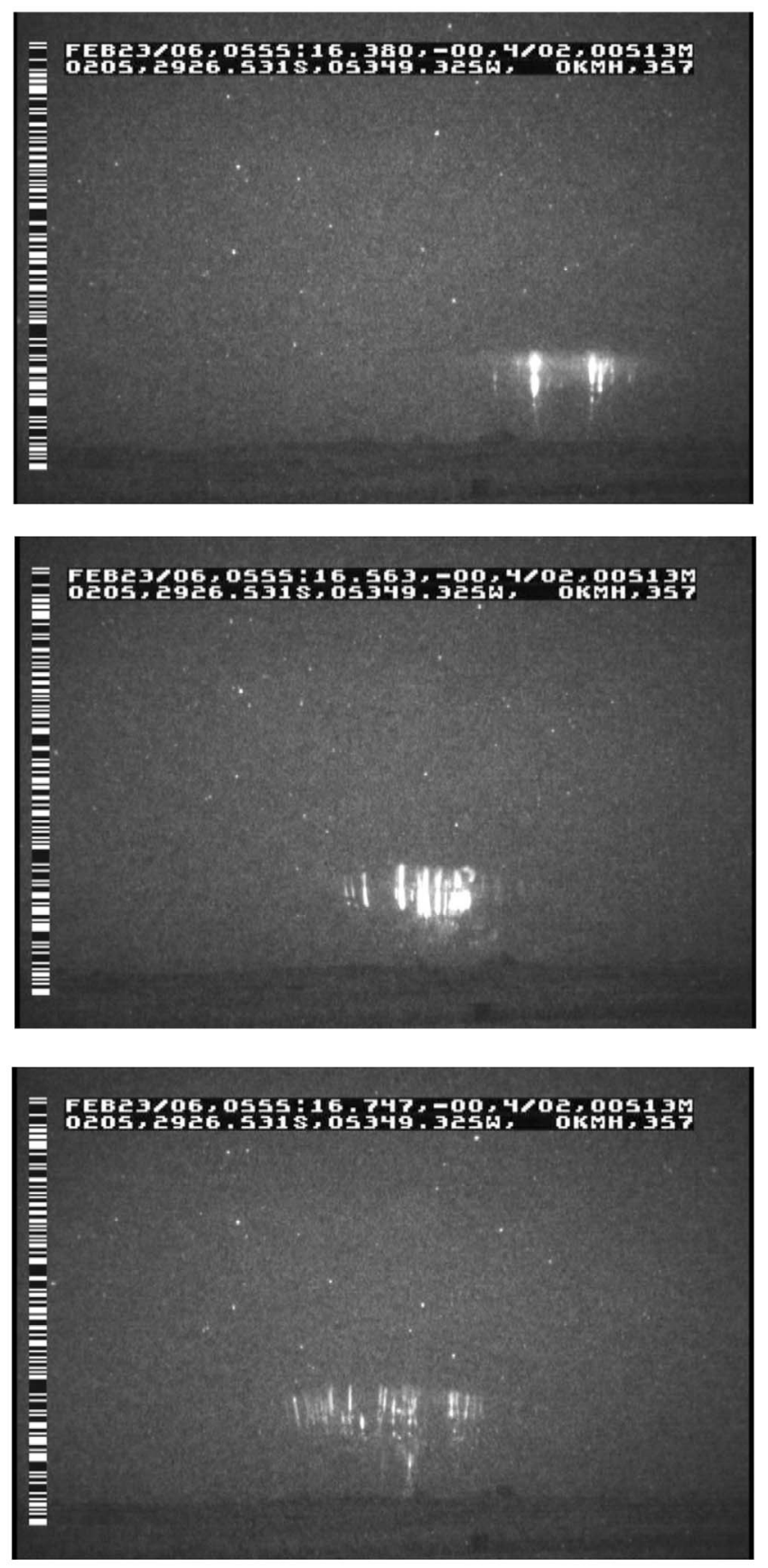

Figure 1. Sequence of multiple sprite events $\sim 800 \mathrm{~km}$ away from INPE Southern Space Observatory (SSO), Brazil, on the night of 22-23 February 2006, above a MCS over Argentina. The first sprite group occurred at 0555:16.380 UT, the second was $183 \mathrm{~ms}$ later, and the third group occurred $184 \mathrm{~ms}$ afterward.

significantly fainter than sprites when recorded using video cameras, but their instantaneous luminosity is much greater.

[5] Sprites are predominantly associated with mesoscale convective systems (MCSs) where vigorous convection leads to large-scale charge separation and strong lightning activity. Lyons et al. [2006] performed a climatological study of TLEproducing systems over the central United States and found that MCSs are the most prolific TLE producers in that region, 
supporting results of previous investigations [Lyons, 1996; São Sabbas and Sentman, 2003]. Over Europe, sprites are also often observed above MCS [Soula et al., 2009]. MCSs are considered to be the largest of the convective thunderstorms and are broadly defined as a cloud system formed by cumulonimbus having a contiguous precipitation area with a lateral extent $>100 \mathrm{~km}$ in at least one direction. They are associated with mesoscale circulation induced by the large collection of convective and stratiform clouds forming them, as well as precipitation [Houze, 2004]. Adapting Orlanski's [1975] classification criteria of mesoscale into three categories according to size and duration of the weather systems, Maddox [1980] defined the meso- $\alpha$, which is the largest, as scale lengths of $250-2,500 \mathrm{~km}$ and durations $>6 \mathrm{~h}$, including MCS in this class.

[6] São Sabbas and Sentman [2003] studied the infrared (IR) cloud top temperature $\left(\mathrm{T}_{\mathrm{c}}\right)$ characteristics and temporalspatial development of one sprite-producing MCS over the central United States that produced 84 sprites. They noted that the sprite activity peaked when total $-\mathrm{CG}$ rate was maximum. This situation occurred in regions where the cloud tops had temperatures between $-72{ }^{\circ} \mathrm{C}$ and $-69^{\circ} \mathrm{C}$, indicating overall strong convection in the core regions of the storm (defined by a cloud shield temperature less than or equal to $-52^{\circ} \mathrm{C}$ ). Even though sprites are mostly generated by +CGs [Boccipio et al., 1995], São Sabbas and Sentman [2003] showed that the overall sprite activity (individual or multiple events) roughly scales according to the thunderstorm overall - CG activity and its convective development in a manner that is presently unknown in details. The parent $+\mathrm{CGs}$ responsible for the sprites occurred in regions $2-3{ }^{\circ} \mathrm{C}$ warmer than the majority of the $+\mathrm{CG}$ population, with temperatures between $-65^{\circ} \mathrm{C}$ and $-63{ }^{\circ} \mathrm{C}$, in the stratiform region.

[7] The climatological study of Lyons et al. [2006] involved characteristics of 46 storm systems that produced more than 2000 TLEs. The data were analyzed on the basis of multiple parameters: the number of TLEs versus the total area $\left(\mathrm{T}_{\mathrm{c}}<-30^{\circ} \mathrm{C}\right)$, TLE location versus reflectivity, thunderstorm overall reflectivity, total continuous precipitation region, TLE parent peak current, sprite time delays, and several other parameters. Most TLEs occurred above regions with $\mathrm{T}_{\mathrm{c}} \sim$ $-65^{\circ} \mathrm{C}$ in agreement with the São Sabbas and Sentman [2003] case study, which seems to have been a typical central United States MCS. The convective cores of the systems analyzed by Lyons at al. [2006] had cloud top temperatures ranging from $-70{ }^{\circ} \mathrm{C}$ to $-75^{\circ} \mathrm{C}$, with the warmest one having $\mathrm{T}_{\mathrm{c}}$ of $-55^{\circ} \mathrm{C}$. They also found that the TLE-generating +CGs were more likely to occur in the trailing stratiform region of the MCS with reflectivity $<20-45 \mathrm{dBZ}$, a minimum $10 \mathrm{dBZ}$ MCS radar echo of $20,000 \mathrm{~km}^{2}$, and convective cores with reflectivity $>55 \mathrm{dBZ}$ and cloud top $\mathrm{T}_{\mathrm{c}}<-55^{\circ} \mathrm{C}$.

[8] Soula et al. [2009] studied the characteristics of 2 MCS that produced 27 sprites each. The system dimensions were smaller than the U.S. MCS. The coldest cloud tops reached $-65^{\circ} \mathrm{C}$ and sprites occurred above regions with $\mathrm{T}_{\mathrm{c}}$ between $-55^{\circ} \mathrm{C}$ and $-50{ }^{\circ} \mathrm{C}$. These temperatures were $\sim 10{ }^{\circ} \mathrm{C}$ warmer than the majority of the U.S. systems, which is consistent with smaller MCS. Differently from the São Sabbas and Sentman [2003] case study, the peak sprite production occurred after a maximum in the total CG activity, when the CG rate was low with $50 \%$ of the discharges being of positive polarity. Soula et al. [2009] attributed the difference to the different size of the systems analyzed, $\sim 1.2 \times 10^{5} \mathrm{~km}^{2}$ and $\sim 2.3 \times 10^{5} \mathrm{~km}^{2}$ during maximum extent for the European and U.S. MCS, respectively.

[9] In the austral summer of 2006, during the months of February and March, we performed an international collaborative campaign in Rio Grande do Sul, the southernmost state of Brazil (the third Sprite Campaign to be performed in Brazil). The main goal was to observe sprites and simultaneously measure the parent lightning and associated electric fields above the thunderstorm, with instrumentation aboard stratospheric balloon payloads. Successful groundbased observations were obtained during two nights of the campaign: 22-23 February 2006 [Taylor et al., 2008] and 3-4 March 2006. More than 400 TLEs and 94 sprites were recorded on these two nights, respectively, making the MCS of 22-23 February one of the most prolific systems ever observed in the world [Thomas et al., 2007]. The observations of the night of 22-23 February 2006 (hereafter referred to as February) form the basis of the present study, in which we undertake a detailed meteorological analysis of the MCS that, while producing large numbers of TLEs, differed significantly from the TLE-producing systems previously studied. The central scientific question addressed in this paper is, Which factors made this MCS such an efficient charge generator throughout its lifetime to consequently have such prolific TLE production?

[10] In this report, we provide a short description of the ground-based optical observation setup and results. We then analyze some characteristics of the TLE-producing storm on the basis of IR satellite imagery and Tropical Rainfall Measuring Mission (TRMM) data, and describe the synoptic meteorological conditions that led to the formation of the convective system. Our analysis is based on the methodology developed by São Sabbas and Sentman [2003] to investigate the temporal-spatial evolution of the cloud top temperatures and their relationship with the location and occurrence rate of CG lightning and TLE locations. As part of the investigation of other geophysical factors that could contribute to the prolific TLE production observed, we document a possible connection between the electrification of MCSs and smoke that was advected into the storm region from 200 large fires occurring at the time all over Paraguay and northern Argentina.

[11] The present paper extends the work of São Sabbas and Sentman [2003], with the goal of developing a robust methodology for forecasting sprite/TLE occurrence anywhere on the globe using only data collected from spacebased platforms, such as satellites. Currently, TLE forecasts, necessary to perform ground-based and airborne observations during scientific campaigns, are highly dependent on lightning data from ground-based detection networks and weather data from satellites and ground-based instrumentation, such as meteorological radar and balloon soundings. These data sets are extremely useful, and their examination has allowed for many successful campaigns in different locations; however, ground-based lightning detection networks, meteorological radar, and a dense network of balloon sounding stations are not available everywhere in the globe. To accomplish this goal, we compare our results with the São Sabbas and Sentman [2003] case study and the Lyons et al. [2006] climatological study of the central United States TLE-producing MCSs, owing to the similar prevailing 


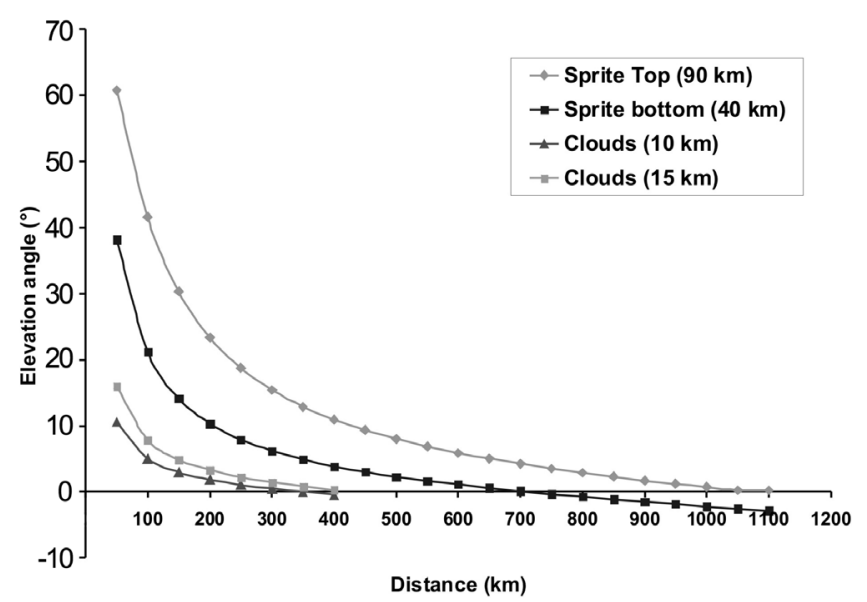

Figure 2. Elevation of different parts of sprites and cloud top altitudes as a function of distance. Since the horizon of the observation site was slightly below $0^{\circ}$ elevation in the direction of the storm and the sky was extremely clear throughout the night, it was possible to see TLEs at great distances.

synoptic meteorological conditions between central United States and central Argentina. The similarities and differences among the TLE-producing MCS are indentified and reported.

[12] In section 2, the TLE observations and supporting data are presented. In section 3 , the prevailing meteorological features of the region and the specific storm conditions at the time of the observations are described. The comparison of TLE observations and MCS parameters is made in section 4, and a possible connection with smoke advecting into the storm region from forest fires in Paraguay and northern Argentina is discussed in section 5. The results of this study are summarized in section 6 .

\section{Observations and Supporting Data}

\subsection{TLE Observations}

[13] The observations were performed from the Southern Space Observatory (SSO/CRS/CCR/INPE - MCT), $\left(29.4^{\circ} \mathrm{S}\right.$, $53.8^{\circ} \mathrm{W}$ ), São Martinho da Serra, Rio Grande do Sul state of Brazil. The observatory, with an altitude of $493 \mathrm{~m}$ above sea level, is the highest point of this region, providing excellent viewing conditions toward the Pampas Plains, where the TLE-producing storm developed. The Plains are a region in northern Argentina and southern Brazil with $<100 \mathrm{~m}$ altitude bounded on the north by Bolivia and Paraguay, on the west by southwestern Brazil, on the south by Uruguay, and on the west by the Andes Mountains.

[14] A total of four cameras from Utah State University USU, two Gen III intensified Xybion ISG780 and two Watec WAT-120 N cameras, as well as one camera from the Brazilian National Institute for Space Research, Instituto Nacional de Pesquisas Espaciais - INPE, a Photonic Science CoolView EM 1000, were installed at the SSO to perform ground observations of TLEs. The cameras were fitted with lenses that provided fields of view between $15.1^{\circ} \times 11.1^{\circ}$ and $48.2^{\circ} \times 34.1^{\circ}$ (horizontal $\times$ vertical) and were positioned to have overlapping fields of view covering an average hor- izontal total azimuth of $\sim 75^{\circ}$ during the observations to maximize the thunderstorm area covered.

[15] An outstanding characteristic of the Argentine Pampas thunderstorm was its prolific TLE production. On the night of 22-23 February 2006, we recorded a total of 444 TLEs, of which 383 were sprites, with the two USU Xybion cameras that covered an average azimuth of $\sim 50^{\circ}-23^{\circ}$. Owing to the large extent of the storm and its distance from the observation site (from 400 to $>1000 \mathrm{~km}$ ), as well as technical difficulties that allowed the retrieving of only the data from the two USU Xybion cameras, these 444 events may be considered a lower limit of the total TLE production of this system. With a rate of 1.3 recorded events per minute during $\sim 6.2$ hours of observation, it is thought to be one of the largest TLE productions ever documented in the history of TLE ground-based observations [Thomas et al., 2007]. In the climatological study involving more than 46 TLE-producing convective systems, of which 44 were MCS, Lyons et al. [2006] estimated that the average TLE production by MCS is 70 events during an average period of 2.3 hours.

[16] The storm initiated its development $>1000 \mathrm{~km}$ toward the southwest of the optical site and moved northeastward throughout the night, in heading toward the SSO. Since the SSO horizon was slightly below $0^{\circ}$ elevation in the direction of the storm and the sky was extremely clear throughout the night, it was possible to see TLEs at great distances; all the events observed occurred at ranges between $\sim 1100$ and $\sim 480 \mathrm{~km}$. Figure 2 shows the elevation of sprite top and bottom and $10-15 \mathrm{~km}$ cloud elevations as a function of distance. Unfortunately, the MCS remained out of the range of the stratospheric balloons that were equipped to collect in situ electromagnetic field data; consequently, no balloon measurements were performed. Sprites were observed as soon as the cameras were turned on (0234 UT), and they were only turned off when predawn sky brightness became too great to continue observations. Astronomical twilight, when the sun is $<18^{\circ}$ below the horizon and the sky ceases to be totally dark, started at 0759 UT. In spite of this, since we were looking toward the west, we still recorded 29 sprites and halos between 0759 UT and 0840 UT; local sunrise was at 0922 UT. The total number of events recorded comprised 263 sprites, 62 halos, and 120 sprite-halos (i.e., sprites embedded in a halo). Sprites formed $\sim 86 \%$ of the total, considering the ones accompanied by halos, and were the dominant type. Figure 1 shows a sequence of monochromatic images of spectacular multiple events $\sim 800 \mathrm{~km}$ away from the recording site. Further details about the campaign setup and operations were described by Thomas et al. [2007] and Taylor et al. [2008].

\subsection{Meteorological Data}

[17] NCEP analysis Global Data Assimilation System (GDAS) data with spatial resolution $\sim 38 \mathrm{~km}$ and 64 vertical levels, as well as balloon soundings in the thunderstorm formation region, were used to diagnose the synoptic and local atmospheric conditions, respectively, that led to the formation of the Argentine thunderstorm (e.g., Figure 3). TRMM satellite data were used to help understand the convective characteristics of the TLE-producing MCS. The TRMM satellite is in a $\sim 400 \mathrm{~km}$ altitude, $35^{\circ}$ inclination nonsun-synchronous orbit and had three obits of interest over the Pampas region during the lifetime of the system: the first time 
(a) 2006/FEB $2212 Z$

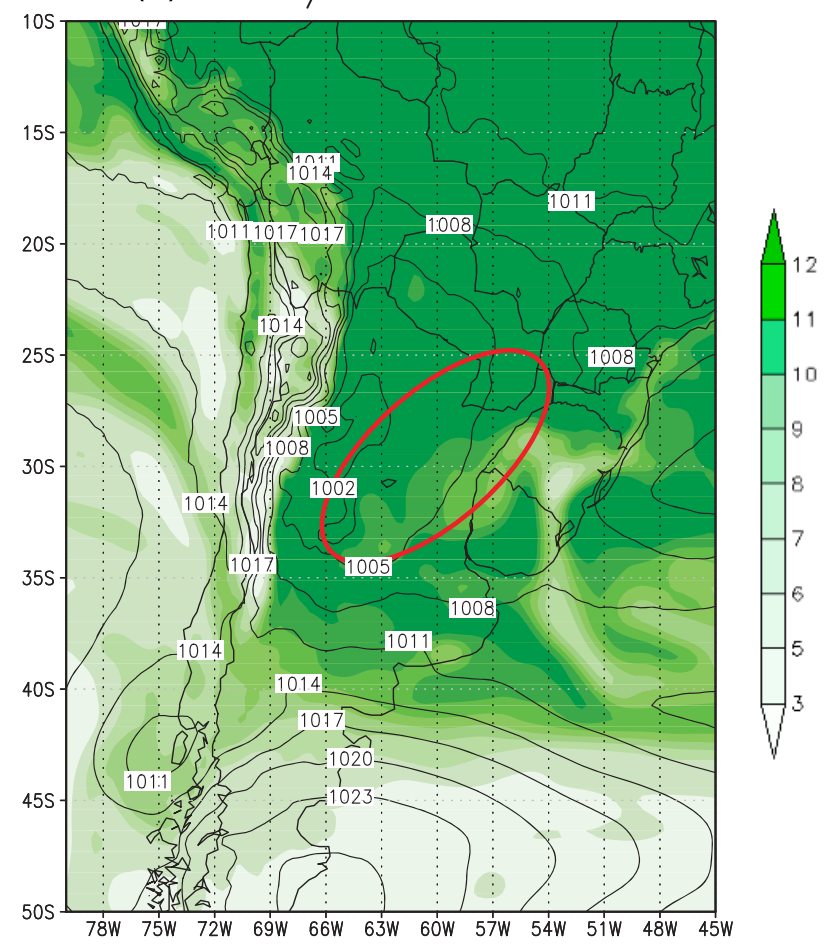

(c) $2006 / F E B ~ 2212 Z$

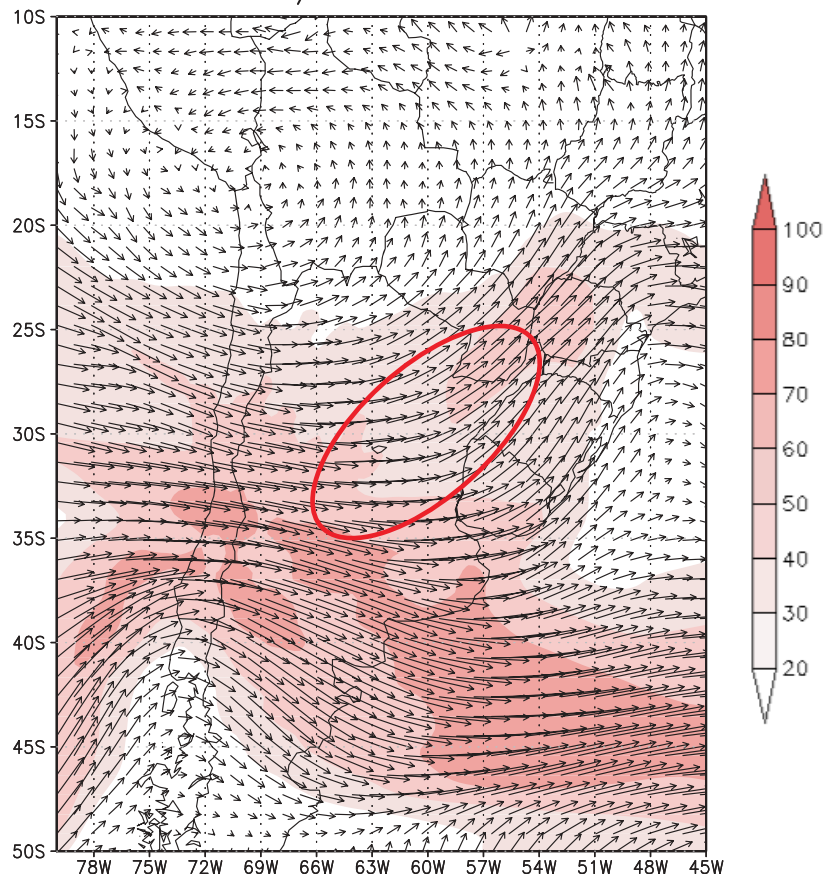

(b) $2006 /$ FEB $2212 Z$

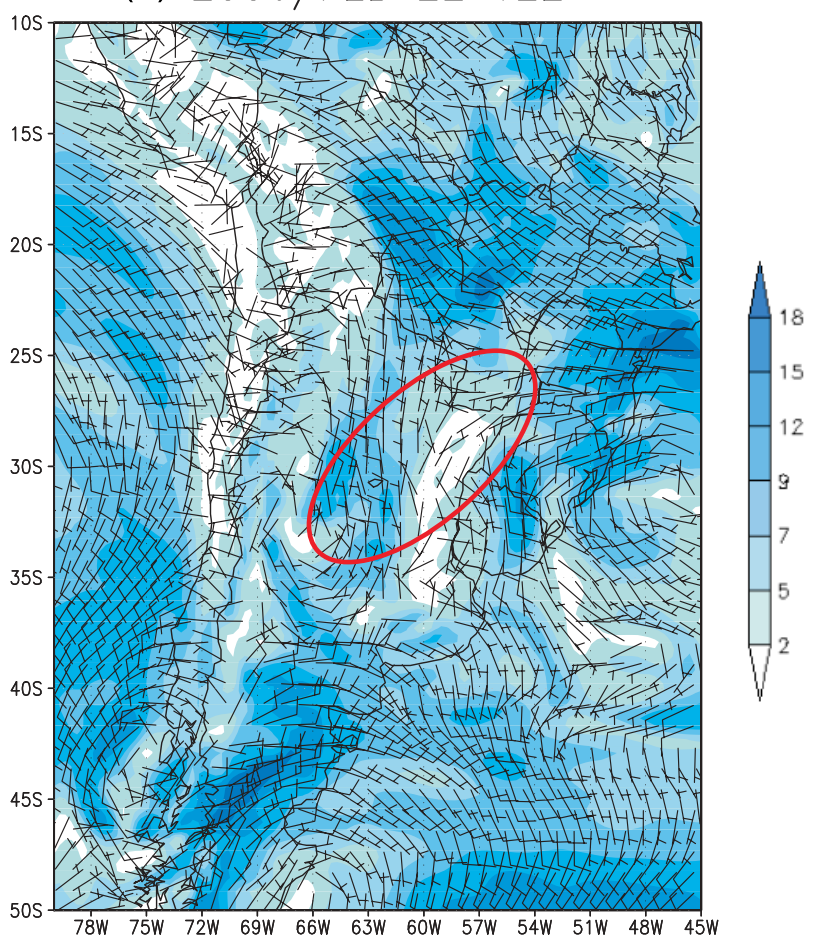

Figure 3. NCEP/GDAS analysis data with $37 \mathrm{~km}$ resolution for 22 February 2006 at 12 UT, 5.5 hours prior to convective activity initiation over central Argentina. (a) Specific humidity in $\mathrm{g} / \mathrm{kg}$ (green) at $850 \mathrm{hPa}$ and reduced pressure at sea level (black isolines). (b) Wind direction and magnitude $(\mathrm{m} / \mathrm{s}$ ) at $850 \mathrm{hPa}$. (c) Wind direction and magnitude $(\mathrm{m} / \mathrm{s})$ at $200 \mathrm{hPa}$. The red ellipsis is the general location of the TLE producing MCS during its lifetime.

on 22 February 2006 around 19 UT and then around 13 UT and 14 UT of the following day. We analyzed the data obtained by the precipitation radar (PR), the passive microwave imager (TMI), Visible and Infrared Scanner (VIRS), and the Lightning Imaging Sensor (LIS), and compared them with some of the results found by Zipser et al. [2006].

[18] The PR was the first meteorological radar aboard a spacecraft. It is a nadir looking active phased array system 
with 128 elements operating at $13.8 \mathrm{GHz}$, with vertical and horizontal resolution of $250 \mathrm{~m}$ and $4.3 \mathrm{~km}$, respectively. The TMI is a $49^{\circ}$ "nadir" looking nine-channel passive microwave radiometer based on the Special Sensor Microwave/ Imager $(\mathrm{SSM} / \mathrm{I})$, with the addition of a pair of $10.7 \mathrm{GHz}$ channels with horizontal and vertical polarizations and a water vapor channel from 22.235 to $21.3 \mathrm{GHz}$. For this work, we used the $85.5 \mathrm{GHz}$ channel, which has an effective footprint ellipse of $9.1 \times 4.6 \mathrm{~km}$ and is a good indicator of precipitating ice column integrated density and/or mass, which are related to updraft strength [Zipser et al., 2006]. The VIRS is a five-channel imaging spectroradiometer with bands in the wavelength range 0.6-12 $\mu \mathrm{m}$ [Kummerow et al., 1998].

\subsection{Satellite Cloud Top Temperatures}

[19] To investigate the relationship between the Argentine system cloud top temperature and the occurrence of CGs and TLEs during the 22 February 20060000 UT and 23 February 20062400 UT period, we compared the TLE locations with the regions corresponding to the pixels of the GOES 12 satellite $10-12 \mu \mathrm{m}$ IR images of South America, taken at $30 \mathrm{~min}$ intervals. The accuracy of the temperature derived from the pixel values is $0.4 \mathrm{~K}$, and the pixel resolution corresponded to approximately $4 \mathrm{~km}$ at the equator. These data were provided by the Brazilian Center for Weather Forecast and Climate Studies, CPTEC/INPE. The satellite is normally scheduled to scan South America every $30 \mathrm{~min}$; however, during the study period, there were several gaps in the measurements, the longest one lasting 1.5 hours, from 0430 UT to 0600 UT, during the peak of TLE activity on 23 February 2006. The satellite images represent the IR temperature measured above South America and cover a region extending approximately from $27.5^{\circ}$ to $-47.8^{\circ}$ latitude and $-26.7^{\circ}$ to $-106.1^{\circ}$ longitude. CPTEC provided processed data, i.e., the count values were already converted into temperature by SeaSpace Corporation automated software (SeaSpace is a provider of satellite ground stations and processing software). The parallax error is negligible because of the position of the geostationary satellite, approximately above the equator and at a longitude of $75^{\circ} \mathrm{W}$; therefore, no parallax correction was applied. To minimize the error due to the MCS displacement and feature development, and to compare the results with the U.S. MCS studied by São Sabbas and Sentman [2003], we considered only sprites and lightning that had occurred up to $15 \mathrm{~min}$ before and after each satellite image.

\subsection{Determination of the Sprite Locations}

[20] The coordinates of the TLEs were estimated from the ground-based image data. Each picture was calibrated using the star field background to determine its azimuth, elevation, and horizontal and vertical fields of view. Then the latitude and longitude of the TLE events were processed, assuming that the altitude of the top of the sprites is, on average, $88 \mathrm{~km}$ [Sentman et al., 1995]. The resulting error is primarily due to the difference between the assumed and the real altitude of the selected sprite top, which includes the uncertainty due to the selection of the pixel corresponding to the highest visible part of the sprite in the image and the error on the sprite top real altitude. The assumed altitude agrees with triangulated sprite top altitudes of $88 \pm 5 \mathrm{~km}$ in the central U.S. [Sentman et al., 1995] which exhibit little event and seasonal variations [Wescott et al., 2001]. For the halos, if the corresponding lightning was known, they were projected on a geographic map and their altitude was estimated when they were perfectly centered on the stroke, similarly to the triangulation work of Wescott et al. [2001]. The mean altitude of $83 \mathrm{~km}$ was then used to determine the location of the other halos, for which the corresponding lightning was not known. The accuracy of this method depends on the distance between the site and the TLE and the error in the altitude assumption. The estimated range of the observed events varied from $\sim 480$ to $\sim 1100 \mathrm{~km}$ from the optical site. For an error of $5 \mathrm{~km}$ on the altitude assumption the error is of approximately $\pm 5 \%$, or a circle with $\sim 22.5 \mathrm{~km}$ radius, for a TLE located $450 \mathrm{~km}$ away from the observation site and approximately $\pm 3 \%$, or $\sim 33.0 \mathrm{~km}$ radius, for a TLE at a $1100 \mathrm{~km}$ range.

\subsection{Lightning Location Data}

[21] The CG geolocations were provided by the World Wide Lightning Location Network (WWLLN) [Rodger et al., 2005]. This global network has a variable detection efficiency that strongly depends on the CG peak current, the number of stations involved in the solution (minimum of 5), and their relative location with respect to each other and to the source. Rodger et al. [2005] performed a detailed analysis of WWLLN's global performance using 20 VLF receiving stations globally distributed. They estimated that the global lightning detection efficiency is $\sim 3 \%$, increasing to $\sim 7 \%$ in South America. Furthermore, $\sim 75 \%$ of WWLLN detected lighting events have peak currents $>50 \mathrm{kA}$. In assessing WWLLN's local performance in a study region of $400 \mathrm{~km}$ radius in the United States (centered on $29^{\circ} \mathrm{N}, 82^{\circ} \mathrm{W}$ ), Jacobson et al. [2006] used 15 stations and data from the Los Alamos Sferic Array (LASA) for ground truth. They concluded that for strokes, the detection efficiency is $\sim 4 \%$ for peak currents $>30 \mathrm{kA}$, and that WWLLN is accurate to $50 \mu \mathrm{s}$ in time and $15-20 \mathrm{~km}$ in location. Both studies included the São Paulo, Brazil station, the only one operating in South America during the campaign. WWLLN does not provide polarity, so we determined the CGs polarity with data collected by Duke University's portable ELF/VLF ( $2 \mathrm{~Hz}$ to $25 \mathrm{kHz}$ ) system installed at the observation site [Li et al., 2008; Taylor et al., 2008].

\section{Meteorological Conditions}

\subsection{General South American Features}

[22] The meteorological conditions associated with the South American Mesoscale Convective Complexes (MCCs), a particularly intense type of MCS, differs from that of North America. For example, Velasco and Fritsch [1987] found that MCSs are typically $\sim 60 \%$ larger and have longer durations than in the United States. These results have been confirmed by follow-on studies by Durkee and Mote [2010] and references therein. Even though TLEs have now been observed globally [e.g., Taylor et al., 2000; Neubert et al., 2001; Fukunishi et al., 2001; Su et al., 2002; Pasko et al., 2002; Pinto et al., 2004; Chen et al., 2008], originating from different types and sizes of thunderstorms, these large mesoscale systems tend to provide the highest TLE occurrence rates, motivating the location of our campaign. Indeed, a study by Sato and Fukunishi [2003] that estimated the global probability of sprite location and occurrence rate (based on 1$100 \mathrm{~Hz}$ ELF measurements) suggested that southern South 


\section{SACO Cordoba Aero}

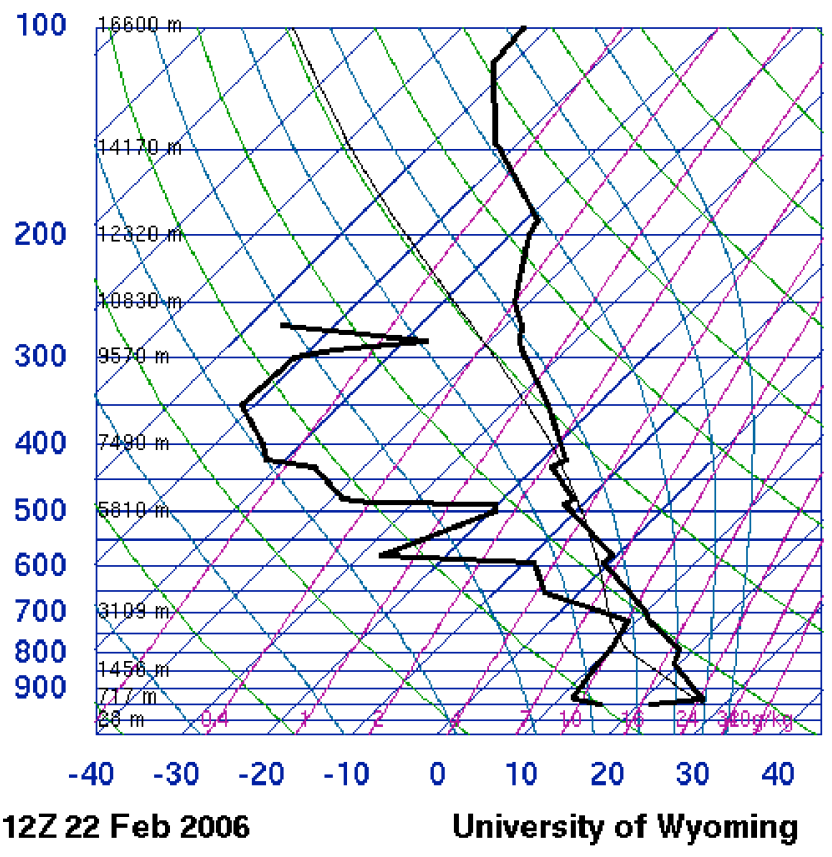

Figure 4. Skew-T diagram at Cordoba $\left(31.32^{\circ} \mathrm{S}, 64.22^{\circ} \mathrm{W}\right)$, the nearest sounding station to the thunderstorm initiation region in Argentina, on 22 February 2006, 12 UT, obtained from University of Wyoming Atmospheric Soundings webpage (available from http://weather.uwyo.edu/upperair/ sounding.html).

America is one of the most active regions of the globe. Chen et al. [2008] performed global observations of TLE using the Imager of Sprites and Upper Atmospheric Lightning (ISUAL) experiment onboard the FORMOSAT-2 satellite, covering $45^{\circ} \mathrm{S}$ to $25^{\circ} \mathrm{N}$ latitude during the northern summer and $25^{\circ} \mathrm{S}$ to $45^{\circ} \mathrm{N}$ latitude during the northern winter. Among other results, they reported the global TLE distribution and occurrence rate on the basis of ISUAL observations, however southern South America was not surveyed owing to the presence of the South Atlantic Magnetic Anomaly (SAMA), thus the actual TLE activity in the study region of this paper is still unknown.

[23] The middle and subtropical South American region, where the Pampas Plains (or Pampas), are located, presents potentially very favorable conditions for the development of deep convection and severe storms, which are defined as capable of producing hail $(2 \mathrm{~cm}$ or more in diameter) when reaching the ground and/or wind gust of $26 \mathrm{~m} / \mathrm{s}$ or more [Nascimento, 2005]. Using NCEP/NCAR reanalysis data [Kalnay et al., 1996] spanning the period 1997 to 1999, Brooks et al. [2003] performed a global climatology to identify regions where such severe storms are most likely to develop. They estimated that for the Americas, the central United States in North America (where most TLE-producing storms have been studied), and the Pampas in South America (where the thunderstorm in the present investigation developed), are the regions with highest probability of severe storms. For central Argentina, where the February MCS developed, $>60$ days per year had atmospheric conditions that favored the development of severe storms.
[24] Zipser et al. [2006] performed a 7-year sample global study, from 1998 to 2004, to map the locations of the most intense thunderstorms of the globe using TRMM data from the Precipitation Radar, Lightning Imaging Sensor, and Visible and Infrared Scanner. Intense storms were defined as having the highest height in the $40 \mathrm{dBZ}$ level of the precipitating data, the lowest minimum polarization corrected temperature (at 37 and $85 \mathrm{GHz}$ ), and the highest lightning flash rate. They found that these three independent parameters seemed to be well correlated as they exhibited similar global spatial distributions. Since the extreme values of each of these parameters indicate intense vertical speeds for the convective updrafts, the maps obtained suggest the location distribution of the most intense thunderstorm in the globe. The Pampas region shows up also as the "hot spot" of South America in this study. The most extreme thunderstorm TRMM observed until 2004 had occurred over Argentina in December 1997; it had the lowest $37 \mathrm{GHz}$ TMI temperature ever observed, reaching $69 \mathrm{~K}$, the $40 \mathrm{dBz}$ echoes reached $19.5 \mathrm{~km}$ altitude, and the VIRS image showed large areas with cloud tops at $-80{ }^{\circ} \mathrm{C}$. Nesbitt et al. [2000] pointed out that the Pampas is, in fact, the region with the most intense MCCs in the world.

[25] An important meteorological feature of South America which was observed during the 22 February period is the South America Low Level Jet (SALLJ) [Marengo et al., 2002; Marengo and Nobre, 2009]. The SALLJ transports tropical moisture into the Pampas from the north. In this case, the wind speed typically reaches $12 \mathrm{~m} / \mathrm{s}$ or more at $850 \mathrm{hPa}$, the shear between $850 \mathrm{hPa}$ and $700 \mathrm{hPa}$ is at least $6 \mathrm{~m} / \mathrm{s}$, and the meridional component is negative with absolute value larger than the zonal component. This jet, or flow, accounts for $45 \%$ of the total precipitation in this region of South America during austral summer and spring [Salio et al., 2007]. Also, the natural evaporation of the Paraguay, Paraná, and Uruguay rivers in this region, which form the La Plata Basin, and other synoptic factors, such as thermally induced local circulation [Salio et al., 2007] create highly favorable conditions for the formation of long lasting nocturnal Convective Systems (CSs). The coupling of SALLJ with a strong low-pressure area at low levels over Argentina, coming from the Pacific [Marengo et al., 2002; Marengo and Nobre, 2009; Silva Dias et al., 2009, and references therein], or with the polar or subtropical jets at high levels [Nascimento, 2005] is also a well-known synoptic feature that transports moisture to the Pampas and favors the occurrence of MCCs and other types of severe storms in that region.

\subsection{The February TLE-Producing MCS}

[26] The thunderstorm responsible for producing the observed TLEs was a Mesoscale Convective System (MCS) that resulted from the merger of several small convective storms (first storms) that had developed earlier over central Argentina. They developed within $\sim 200 \mathrm{~km}$ radius of the city of Cordoba $\left(31.32^{\circ} \mathrm{S}, 64.22^{\circ} \mathrm{W}\right)$, where the nearest balloon sounding station was located. The convective activity in this region was dynamically supported by upper-level divergence in the transition zone of an upper level tropical anticyclonic circulation known as the Bolivian High [Virji, 1981; Figueroa et al., 1995; Gandu and Dias, 1998] and a midlatitude cyclone vortex (Figure 3b). This feature overcame the locally unfavorable preexisting thermodynamic conditions, shown at the 1200 UT skew-T diagram from Cordoba (Figure 4). 
(a) Day 23/02/06 Time 07:30 UT Temperature $\left({ }^{\circ} \mathrm{C}\right)$

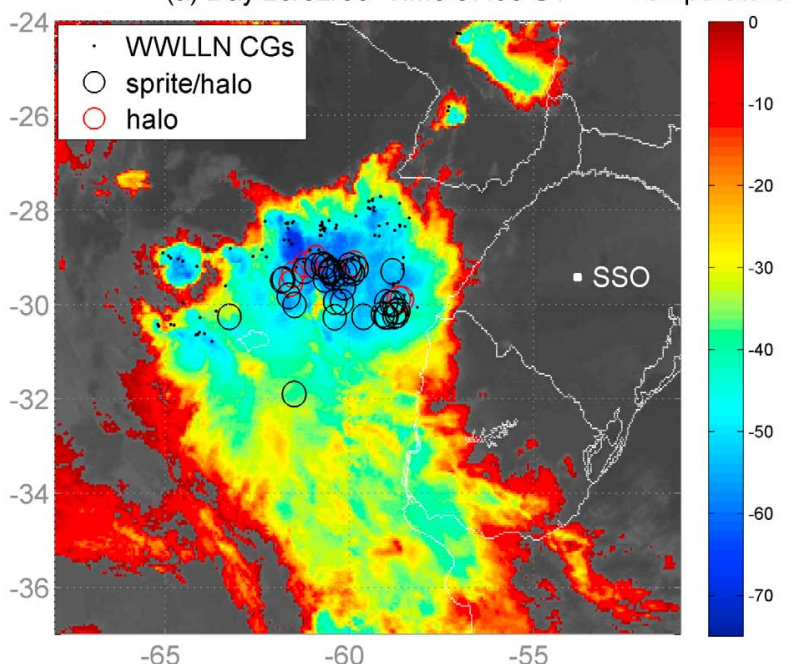

(b) Day 22/02/06 Time 19:00 UT

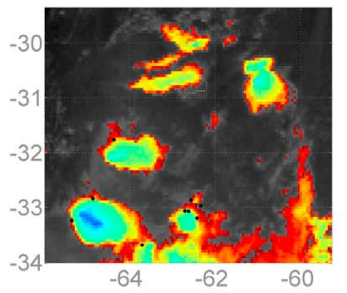

(d) Day 23/02/06 Time 06:30 UT

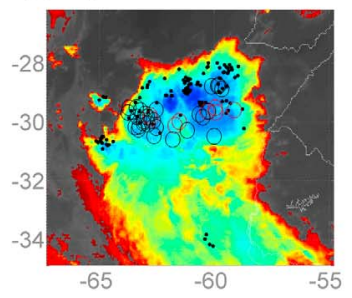

$-65$

Figure 5. Cloudtop temperature maps of the Argentine TLE producing storm showing TLE locations, WWLLN CG locations, and the location of the ground optical site at INPE's SSO. The large image shows the storm during its maximum extent and the smaller images show different stages of the MCS development.

The Convective Available Potential Energy (CAPE) was very small, $\sim 57$ and $\sim 87 \mathrm{~J} / \mathrm{kg}$, and there was strong Convection Inhibition (CIN), with values of -424 and $-457 \mathrm{~J} / \mathrm{kg}$, despite a drier layer above a moist layer near the surface and the presence of thermal inversion. Two other sounding stations in the same general area in northeastern Argentina and southwestern Brazil presented similar conditions (not shown). Gust winds of $\sim 39 \mathrm{~km} / \mathrm{h}$ were measured in Cordoba on the $22 \mathrm{nd}$, and of $\sim 45 \mathrm{~km} / \mathrm{h}$ and $\sim 50 \mathrm{~km} / \mathrm{h}$ were measured in Cordoba and Resistencia $\left(27.45^{\circ} \mathrm{S}, 59.05^{\circ} \mathrm{W}\right)$, respectively, on the 23 rd associated with this thunderstorm. Precipitation was relatively low, $\sim 5 \mathrm{~mm}$ and $\sim 6 \mathrm{~mm}$ in Cordoba and Resistencia, respectively.

[27] Figure 3 shows NCEP analysis data for 22 February 2006 at 12 UT, 5.5 hours prior to convective activity initiation over central Argentina: Figure 3a shows specific humidity at $850 \mathrm{hPa}$ and reduced pressure at sea level; Figure $3 \mathrm{~b}$ shows wind direction and magnitude at $850 \mathrm{hPa}$, and Figure $3 \mathrm{c}$ shows wind direction and magnitude at $200 \mathrm{hPa}$. The convective activity initiated during the establishment of a cold front that reorganized the low-level flow at the prefrontal region redistributing moisture favoring convergence and upward motions in that area. The genesis of this front was associated with a northeastward displacement of an upper air cold vortex, or closed low, coming across the Andes from the Pacific Ocean and into the central region of Argentina (Figure $3 b$ ). When this low-pressure system reached central Argentina, a strong low-level warm moist air flow from the Amazon and central Brazil was observed, advecting moisture to higher latitudes feeding the prefrontal region (Figure 3a), where the first convective storms that would merge to form the MCS developed. As mentioned before the presence of the Bolivia High, which is normally accompanied by a thermal low pressure at the surface and low levels (Chaco Low), helped in organizing low-level convergence, upward vertical motions, divergence aloft and convective activity (Figure $3 \mathrm{c}$ ).

[28] At 1200 UT on 22 February 2006 the SALLJ was well characterized over central Argentina (Figure 3b). Similarly to what was reported by Marengo et al. [2002] and Marengo and Nobre [2009], the SALLJ was present over Brazil on the two previous days, 20 and 21 February 2006, with its maximum intensity at 0600 UT and 1200 UT, respectively. On each of the three days when the jet was present, low-level moisture was advected from the Amazon basin, such that at $1200 \mathrm{UT}$ a specific humidity of $11 \mathrm{~g} / \mathrm{kg}$ was available for thunderstorm initiation (Figure 3a). In a study of 10 MCSs in the same general region between 2005 and 2006, Anabor et al. [2008] found the same values of specific humidity. They also observed the presence of the Chaco Low centered at $30^{\circ} \mathrm{S}$, contributing to the organization of the Amazonic flow into this region.

\section{Comparison of TLE Observations With MCS Convective Characteristics}

[29] Figure 5 (see Movie S1) shows the temporal and spatial development of the TLE-producing system, in which the first image is its maximum extent. ${ }^{1}$ The storms that evolved to form the TLE-producing MCS were first detected at $1730 \mathrm{UT}$ 22 February 2006, started to be tracked at 1900 UT (Figure 5b) and began to merge $2 \mathrm{~h}$ later (Figure 5c). We adapted the Maddox [1980] and São Sabbas and Sentman [2003] definition of a MCS as a system with contiguous cloud cover with $\mathrm{T}_{\mathrm{c}}<-34^{\circ} \mathrm{C}$, a minimum area of $100,000 \mathrm{~km}^{2}$, and inner clouds indicative of convection with $\mathrm{T}_{\mathrm{c}}<-54^{\circ} \mathrm{C}$ with minimum area of $50,000 \mathrm{~km}^{2}$. Applying these criteria, the TLE convective system that initiated at 1900 UT became a MCS only 9.5-11.5 hours later, between 0430 UT and 0600 UT of the next day (Figure 5d), when there was a data gap.

[30] Owing to several gaps in the GOES data, we could not determine precisely when the system became a MCS or the total duration of the storm; however, we tracked it until 1500 UT, 23 February 2006 (not shown) and estimated that it had a minimum lifetime of 20 hours, 8.5 of those hours as an MCS. At $0730 \mathrm{UT}$, the storm reached its maximum extent of $\sim 430,000 \mathrm{~km}^{2}$ (Figure 5a). The MCS never

\footnotetext{
${ }^{1}$ Auxiliary materials are available in the HTML. doi:10.1029/ 2009JA014857.
} 
Table 1. TLE Producing MCS Convective Characteristics

\begin{tabular}{|c|c|c|c|c|c|c|c|c|c|}
\hline Region & Initiation & Lifetime & $\begin{array}{c}\text { Time } \\
\text { of Max. Extent }\end{array}$ & $\begin{array}{l}\text { Max. Extent } \\
\left(\mathrm{km}^{2}\right)\end{array}$ & $\begin{array}{l}\text { Diameter } \\
(\mathrm{km})\end{array}$ & $\begin{array}{c}\text { Min } \mathrm{T}_{\text {core }} \\
\left({ }^{\circ} \mathrm{C}\right)\end{array}$ & $\begin{array}{l}\mathrm{T}_{\mathrm{av}} \\
\left({ }^{\circ} \mathrm{C}\right)\end{array}$ & $\begin{array}{c}\text { Convective Area } \\
\left(\mathrm{km}^{2}\right)\end{array}$ & $\begin{array}{l}\text { Time Min. } \\
\mathrm{T}_{\text {core }}\end{array}$ \\
\hline 1 & $1900 \mathrm{UT}$ & $1.0 \mathrm{~h}$ & $2000 \mathrm{UT}$ & 1074 & 37 & -62.2 & -58.1 & 61 & $2030 \mathrm{UT}$ \\
\hline 2 & $2030 \mathrm{UT}$ & $2.0 \mathrm{~h}$ & $2200 \mathrm{UT}$ & 653 & 29 & -61.1 & -57.0 & 87 & $2200 \mathrm{UT}$ \\
\hline 3 & $2300 \mathrm{UT}$ & $4.5 \mathrm{~h}$ & $2300 \mathrm{UT}$ & 804 & 32 & -65.4 & -57.8 & 62 & $2300 \mathrm{UT}$ \\
\hline 4 & $2230 \mathrm{UT}$ & $0.5 \mathrm{~h}$ & $2230 \mathrm{UT}$ & 132 & 13 & -57.2 & -56.1 & 27 & $2230 \mathrm{UT}$ \\
\hline 5 & $2230 \mathrm{UT}$ & $0.5 \mathrm{~h}$ & $2230 \mathrm{UT}$ & 77 & 10 & -56.2 & -55.5 & 42 & $2230 \mathrm{UT}$ \\
\hline 6 & $2230 \mathrm{UT}$ & $1.5 \mathrm{~h}$ & $0000 \mathrm{UT}$ & 517 & 26 & -60.8 & -57.0 & 61 & $2300 \mathrm{UT}$ \\
\hline 7 & $2330 \mathrm{UT}$ & $0.5 \mathrm{~h}$ & $2330 \mathrm{UT}$ & 81 & 10 & -54.8 & -55.0 & 13 & $2330 \mathrm{UT}$ \\
\hline 8 & $2330 \mathrm{UT}$ & $4.5 \mathrm{~h}$ & 0130 UT & 8208 & 102 & -72.4 & -60.0 & 858 & 0130 UT \\
\hline 9 & 0100 UT & $0.5 \mathrm{~h}$ & 0100 UT & 210 & 16 & -58.6 & -56.6 & 64 & $0100 \mathrm{UT}$ \\
\hline 10 & 0130 UT & $2.0 \mathrm{~h}$ & 0230 UT & 727 & 30 & -60.4 & -55.8 & 36 & $0230 \mathrm{UT}$ \\
\hline 11 & 0130 UT & $2.5 \mathrm{~h}$ & 0300 UT & 1555 & 44 & -72.4 & -59.0 & 287 & $0400 \mathrm{UT}$ \\
\hline 12 & 0130 UT & $2.5 \mathrm{~h}$ & 0330 UT & 3421 & 66 & -65.0 & -57.3 & 144 & $0230 \mathrm{UT}$ \\
\hline 13 & 0130 UT & $1.5 \mathrm{~h}$ & $0300 \mathrm{UT}$ & 322 & 20 & -60.4 & -56.1 & 42 & $0300 \mathrm{UT}$ \\
\hline 14 & $0330 \mathrm{UT}$ & $0.5 \mathrm{~h}$ & 0330 UT & 178 & 15 & -55.2 & -54.5 & 26 & $0330 \mathrm{UT}$ \\
\hline 15 & $0330 \mathrm{UT}$ & $0.5 \mathrm{~h}$ & $0400 \mathrm{UT}$ & 1074 & 37 & -56.1 & -56.2 & 177 & $0400 \mathrm{UT}$ \\
\hline 16 & $0230 \mathrm{UT}$ & $1.5 \mathrm{~h}$ & $0400 \mathrm{UT}$ & 3364 & 65 & -67.9 & -58.8 & 88 & $0400 \mathrm{UT}$ \\
\hline 17 & 0630 UT & $8.5 \mathrm{~h}$ & $1030 \mathrm{UT}$ & 57773 & 271 & -74.3 & -58.5 & 937 & $0630 \mathrm{UT}$ \\
\hline 18 & $0630 \mathrm{UT}$ & $1.0 \mathrm{~h}$ & $0700 \mathrm{UT}$ & 956 & 35 & -59.3 & -55.9 & 24 & 0630 UT \\
\hline 19 & 0730 UT & $0.5 \mathrm{~h}$ & 0730 UT & 426 & 23 & -59.3 & -55.9 & 24 & $0730 \mathrm{UT}$ \\
\hline
\end{tabular}

became organized enough or round enough (eccentricity $>0.7$ at maximum extent) to be considered an MCC in accord with the data of Maddox [1980]. The overall cloud shield, with $\mathrm{T}_{\mathrm{c}}<-34^{\circ} \mathrm{C}$, often had "holes", i.e., areas with $\mathrm{T}_{\mathrm{c}}>-34^{\circ} \mathrm{C}$ and, during the decay phase, entered an oscillation mode with $\sim 1$ hour periodicity of connecting and disconnecting its southern portion to an extensive mesoscale cloud system with insignificant convective regions. Owing to this oscillation, to calculate a realistic area for its cloud shield, we artificially determined the MCS southern border when it was connected to the second system. The cut was performed in places where they naturally disconnected on follow-up images.

[31] This convective system had a multicellular structure presenting several convective regions, defined as areas with $\mathrm{T}_{\mathrm{c}}<-54^{\circ} \mathrm{C}$, that remained relatively isolated from each other. To track them and to determine their convective cores on the GOES IR imagery, we applied the methodology developed by São Sabbas et al. [2009] to identify and estimate the dimensions, duration, intensity, and tropopause overshoot of convective cores capable of exciting gravity waves on the basis of satellite IR imagery. For the Argentine MCS, we calculated the average temperature $\mathrm{T}_{\mathrm{av}}$ of the convective regions and calculated the difference between the temperature of the pixels that composed the regions and their average value, $\Delta \mathrm{T}=\mathrm{T}_{\text {pixel }}-\mathrm{T}_{\mathrm{av}}$. The center of the convective cores was chosen to be the pixels with lowest temperature $\left(\mathrm{T}_{\text {core }}\right)$, and their size was determined to include the surrounding pixels with $\Delta \mathrm{T}<\mathrm{T}_{\text {core }} / 2$.

[32] Using this technique, 19 convective regions were identified and tracked within the TLE-producing thunderstorm. Their estimated parameters, initiation time, lifetime duration, time of maximum extent, maximim extent, diameter at maximum extent, minimum temperature a convective core reaches throughout the lifetime of the region, average temperature of the convective core at that time, area of the convective core and time when the minimum temperature is reached, are presented on the columns 2 to 10 of Table 1, respectively. These were the largest convective regions of the system; their areas were between $\sim 77 \mathrm{~km}^{2}$ and $\sim 57,773 \mathrm{~km}^{2}$ during maximum extent, and they lasted $\sim 30 \mathrm{~min}$ to $\sim 8.5$ hours, respectively. The duration of the largest region was a lower estimate due to the 1.5 hours gap in the data on 23 February 2006, from 0430 UT to 0600 UT. Assuming that the regions were circular, their effective diameters were then $\sim 10 \mathrm{~km}$ and $\sim 271 \mathrm{~km}$, respectively. The minimum temperature that the convective cores reached during their peak activity varied between $-60^{\circ} \mathrm{C}$ and $-74^{\circ} \mathrm{C}$, with a corresponding altitude of $\sim 14.0 \mathrm{~km}$ and $16.7 \mathrm{~km}$, estimated by making a simple comparison between $\mathrm{T}_{\text {core }}$ and the balloon soundings from Cordoba on 22 February 2006 at 1200 UT [São Sabbas et al., 2009]. None of the convective cores reached the tropopause, whose temperature was estimated at $-75^{\circ} \mathrm{C}$, corresponding to an altitude of $\sim 17.1 \mathrm{~km}$, also based on Cordoba soundings (Figure 6). Therefore, the convection within this system was not as deep as usually observed in

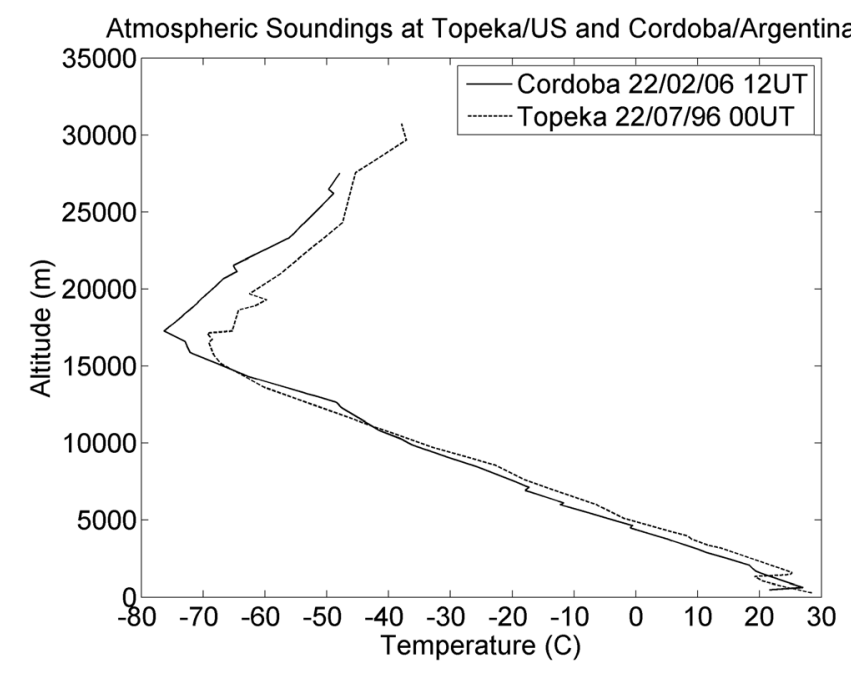

Figure 6. Atmospheric temperature profile of locations near the thunderstorm path for the U.S. TLE producing MCS studied by São Sabbas and Sentman [2003], dashed line, and Argentine TLE producing storm of this study, solid line. 
other TLE-producing MCS whose convective cores generally reach and often overshoot the tropopause.

[33] The TRMM satellite had six orbits passing over Argentina between 15 UT of 22 February 2006 and 18 UT of the following day. However only three of the passes, the 17 UT and 19 UT on the 22nd, and the 13 UT on the $23 \mathrm{rd}$, had the TLE-producing storm in the field of view. Unfortunately, the first two passes were during the early development stage of the first convective storms, and the last one was during the MCS decay phase, during daytime, after TLE observation had ended. There was no TRMM data during the prime thunderstorm time and TLE production. LIS recorded the lighting discharges of the 19 UT and 13 UT passes, registering $\sim 4$ min of activity; however, on the 19 UT pass, none of the flashes recorded belonged to the studied thunderstorm. On the 13 UT, LIS registered 133 flashes during the 4 min period, detecting a $\sim 33 \mathrm{~min}^{-1}$ lightning rate in the TLEproducing system decay phase.

[34] The VIRS and TMI recorded data corresponding to the studied storm in all three orbits (17 UT, 19 UT, and 13 UT), but the PR only scanned the storm on the 13 UT orbit. The PR and VIRS data for the 13 UT 23 February 2006 pass are shown on Figure 7. Figure 7a is a horizontal cross section at $3.5 \mathrm{~km}$ of the PR reflectivity echoes superimposed on the VIRS image. Figure $7 \mathrm{~b}$ exhibits a vertical cross section of the PR data along the black line on the PR horizontal cross section on the top. The decaying TLE-producing MCS is indicated by the black ellipsis on the PR-VIS composite (Figure 7a). The vertical cross section shows that the cloud tops of the scanned region, defined as the $20 \mathrm{dBz}$ echoes [Zipser et al., 2006], were at $\sim 5.5 \mathrm{~km}$ altitude and no $40 \mathrm{dBZ}$ echo was present, showing low convective activity and a more stratiform structure, agreeing with the average $-40{ }^{\circ} \mathrm{C}$ cloud cover shown on the 1330 UT color-coded GOES IR temperatures (Figure 5e). Figure 8 shows the $85.5 \mathrm{GHz}$ TMI brightness temperature image of the 18 UT 22 February 2006 pass zoomed onto the first storm that grew into the TLE-producing MCS merging with others. Figure 8 demonstrates that the convective core reached the minimum brightness temperature of $84 \mathrm{~K}$, indicating a significant concentration of precipitating ice in its small convective core [Zipser et al., 2006], which is important for cloud electrification processes [Takahashi, 1978; Ushio et al., 2001; Wang and Liao, 2006; Zipser and Lutz, 1994]. The $84 \mathrm{~K}$ is within the lowest values reported on Zipser et al. [2006] severe storm global distribution.

[35] The lifetime of the studied thunderstorm can be subdivided in two parts: before and after it developed a convective region that was large enough to give it MCS status, shown in the 0630 UT image (Figure 5d, first one after the gap). Before $0630 \mathrm{UT}$, all convective regions had convective cores with minimum temperature between $-59{ }^{\circ} \mathrm{C}$ and $-65^{\circ} \mathrm{C}$ and corresponding average $\Delta \mathrm{Ts}$ of $\sim-3{ }^{\circ} \mathrm{C}$ and $-7{ }^{\circ} \mathrm{C}$, respectively. The exceptions were Regions 10 and 13 with convective cores that reached $-72{ }^{\circ} \mathrm{C}$ but had a $\Delta \mathrm{T}$ of $\sim-12{ }^{\circ} \mathrm{C}$ and $-13{ }^{\circ} \mathrm{C}$, respectively. The deviation from the average temperatures shows how significant the minimum temperature was, e.g., if $\mathrm{T}_{\text {core }}$ is low and $|\Delta \mathrm{T}|$ is small, it indicates that the whole convective core reached a high altitude and convection was vigorous inside it. However, since $|\Delta \mathrm{T}|$ was large for the lowest $\mathrm{T}_{\text {core }}$, just a small area within the core had strong updrafts. In the pre-MCS phase, the convective cores, and therefore the convective regions, had only moderate convective activity. After 0630 UT, only 3 independent convective regions developed, and the largest one, Region 17 , reached an area of $57,773 \mathrm{~km}^{2}$. The minimum $\mathrm{T}_{\text {core }}$ values at this phase were between $-59{ }^{\circ} \mathrm{C}$ and $-74{ }^{\circ} \mathrm{C}$, with $\Delta \mathrm{T}$ of $\sim-3{ }^{\circ} \mathrm{C}$ and $-16{ }^{\circ} \mathrm{C}$, respectively; however, in this case, region 17 had larger areas with temperatures below $-58{ }^{\circ} \mathrm{C}$, which were lower than before and indicative of more vigorous convection than before.

[36] Another interesting feature of this TLE-producing thunderstorm is that the convective regions did not merge and remained relatively isolated from each other during their life cycle, developing their own stratiform clouds following the direction of the subtropical jet at high levels. It was within this environment and above these "individual stratiform regions" and the general cloud cover $\left(-54^{\circ} \mathrm{C}<\mathrm{Tc}<-34{ }^{\circ} \mathrm{C}\right)$ that TLEs were first observed at $\sim 0230$ UT on 23 February 2006 and throughout the rest of the night. Since region 17 presented deeper convection and was large, dominating after $0630 \mathrm{UT}$, the TLEs occurred above areas with lower temperatures at this development phase (MCS) of the system as shown in the spectrograms on Figure 9. Since the system did not have a well-defined stratiform region either at the front, back, or parallel to the convective regions [Parker and Johnson, 2000; Houze, 2004], and TLEs occurred above these individual stratiform areas, the system did not present a preferential TLE-producing region relative to the movement of the storm (northeastward at $\sim 60 \mathrm{~km} / \mathrm{h}$ ) and could not be classified as a back trailing, front leading, or parallel stratiform MCS. By contrast, in the United States and in Europe, sprites have been observed to mainly occur above the back trailing stratiform region of the MCS [Lyons, 1996; São Sabbas and Sentman, 2003; Lyons et al., 2006; Soula et al., 2009].

[37] Figure 9 shows the time-temperature spectrograms with the temporal evolution of the occurrence rates for sprites, halos, and WWLLN CGs associated with different cloud top temperatures. Sprites were associated with cloud top regions with an average $\mathrm{T}_{\mathrm{c}}$ of approximately $-45^{\circ} \mathrm{C}$ in the beginning of the observations and $-53{ }^{\circ} \mathrm{C}$ at the end of the night, corresponding to altitudes of $\sim 11.7 \mathrm{~km}$ and $\sim 13.2 \mathrm{~km}$, respectively. Halos, on the other hand, occurred above regions with $\mathrm{T}_{\mathrm{c}}$ of approximately $-54{ }^{\circ} \mathrm{C}$ throughout the observation period. The CGs were associated with cloud top temperatures of $-20^{\circ} \mathrm{C}(\sim 7.5 \mathrm{~km})$ at the beginning of the Argentine storm observations. Their occurrence rates grew with decreasing temperatures until a maximum activity was reached in regions with $\mathrm{T}_{\mathrm{c}}-50{ }^{\circ} \mathrm{C}(13.3 \mathrm{~km})$. After $\sim 2 \mathrm{hr}$, the $C G$ rate decreased in association with higher $T_{c}$ as the thunderstorm dissipated (Figure 9c). The sprite and $\mathrm{CG}$ behaviors reflect the development of the thunderstorm itself. From the superposition of CG and TLE geolocations on the satellite IR images (Figure 5), we observed that the CGs detected by WWLLN were distributed over the general cloud cover and around the convective cores, and sprites were over the surrounding stratiform areas and general cloud cover. As the storm developed, the convective cores became colder as well as the stratiform regions.

[38] To determine the impact of the TLE location error on the cloud top temperature analysis described above (estimated to approximately $\pm 22.5-33.0 \mathrm{~km}$ and represented by small circles on Figure 5, we calculated the average temper- 
(a)
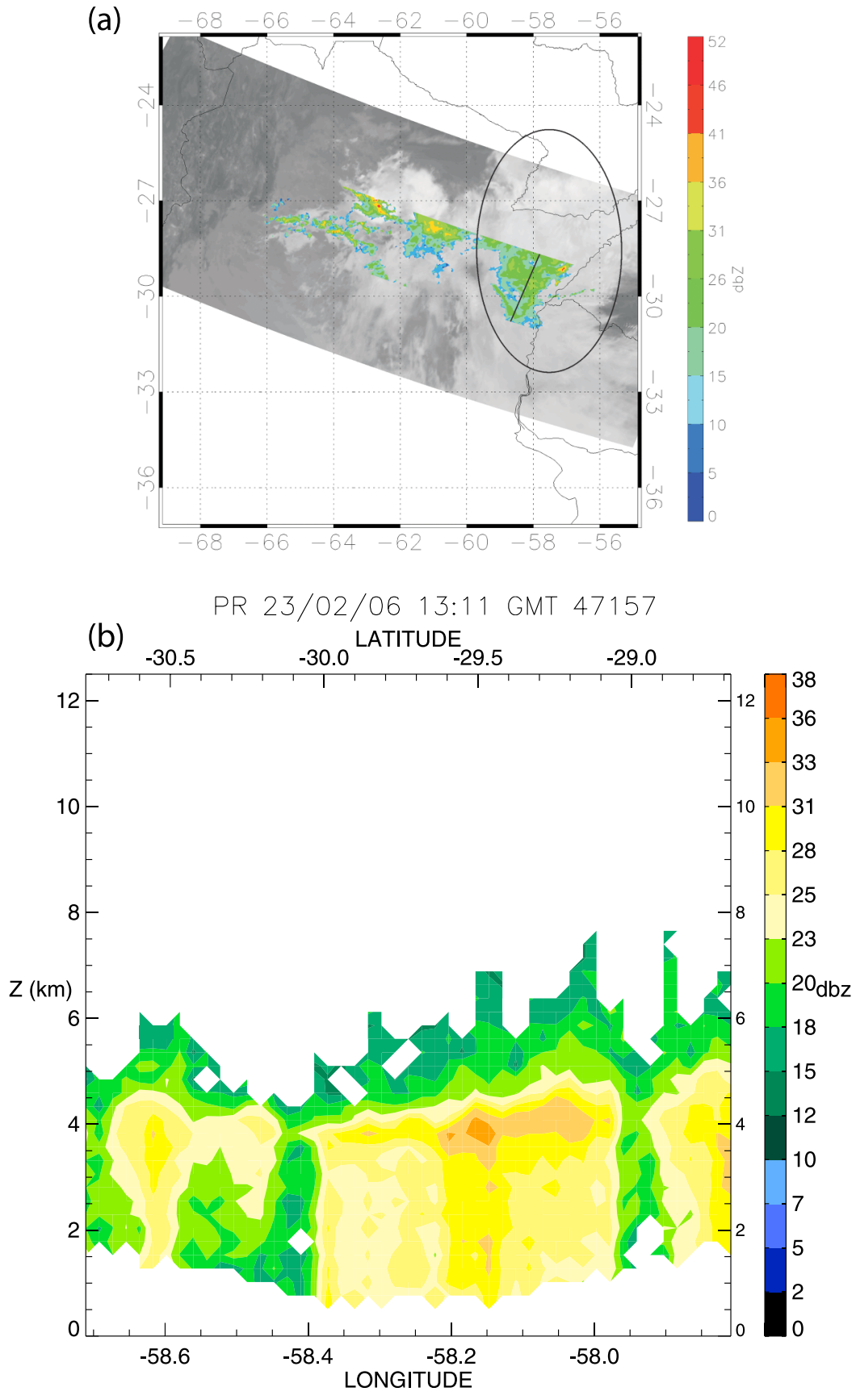

Figure 7. PR and VIRS data for the 13 UT 23 February 2006 pass. (a) A composite showing a horizontal cross section at $3.5 \mathrm{~km}$ of the PR reflectivity echoes superimposed on the VIRS image. The black ellipse shows the decaying TLE producing storm. (b) A vertical cross section of the PR data along the black line on the PR horizontal cross section at the top.

ature of a $66 \mathrm{~km}$ diameter circle centered on all the sprites and sprite-halos for which there were IR images available (218 events) and the temperature deviation $(\Delta \mathrm{T})$ of the pixel corresponding to the estimated sprite location. Excluding three outliers whose circles included areas over land, because there were in the border of the clouds, the average absolute $\Delta \mathrm{T}$ was $1.4 \pm 1.3^{\circ} \mathrm{C}$, indicating that the location error did not produce a significant impact on the cloud top temperature analysis.
[39] Figure 10 shows the temporal evolution of sprite and TLE occurrence rate and WWLLN stroke rate in $30 \mathrm{~min}$ intervals on the first and second rows, respectively. The temporal evolution of the main convective region (region 17), and the general cloud shield are on the third and fourth rows, respectively. A total of 47 TLEs, $\sim 11 \%$, were associated with WWLLN detected CGs. Duke's ELF/VLF portable system determined that $\sim 40 \%$ of all CGs detected by WWLLN on 23 February 2006 were negative and $\sim 27 \%$ were positive CGs; the polarity of the other $\sim 33 \%$ CGs could not be established. 


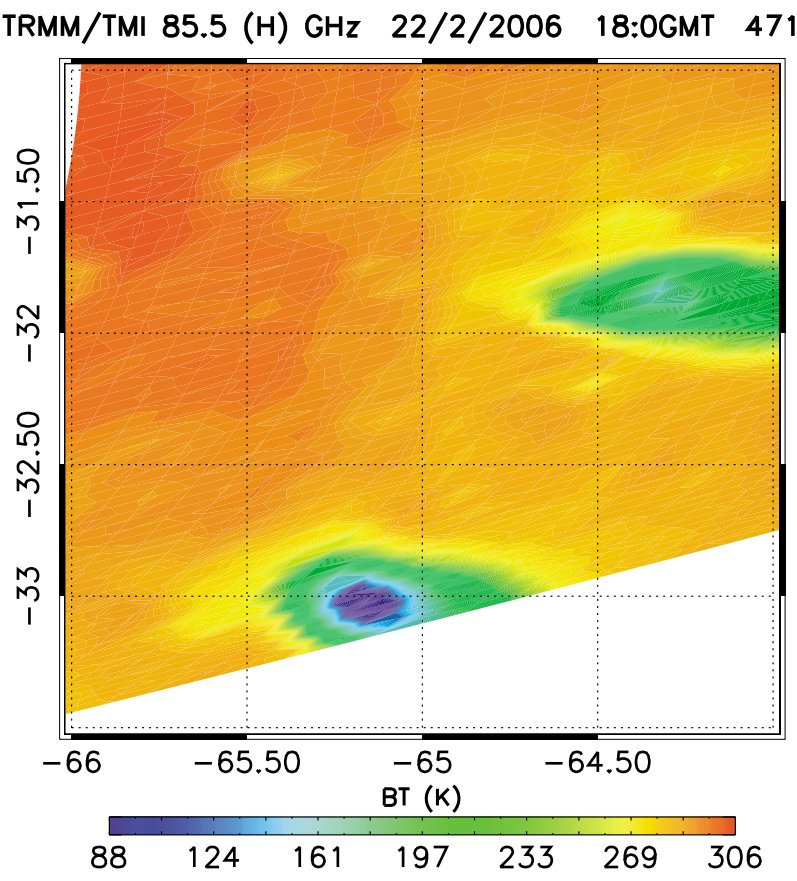

Figure 8. TMI brightness temperature image of the 18 UT 22 February 2006 pass zoomed to show the details of the first storm that grew into the TLE producing MCS merging with others (centered at $\sim 33^{\circ} \mathrm{S}$ and $\sim 65.2^{\circ} \mathrm{W}$ ).

The maximum in the sprite and TLE rates corresponded to the maximum in the total number of WWLLN detected CGs. Assuming that -CGs were indeed the dominant polarity, as in the majority of thunderstorms, and since most of the CGs detected were related to the convective regions, this coincidence reflects the development of the thunderstorm convective activity.

\section{Discussion: Possible Effect of Smoke From Forest Fires in Paraguay and Northern Argentina on MCS Electrification}

[40] As described above, a comparison between the Argentine TLE-producing storm analyzed here and the U.S. systems studied by São Sabbas and Sentman [2003] and Lyons et al. [2006] showed that the cloud top temperatures were in general $\sim 10-20{ }^{\circ} \mathrm{C}$ warmer for the Argentine storm (this study) than what was reported in the U.S. cases and that convection was not as deep in the Argentine storm as in the U.S. ones. On the other hand, the dominant synoptic characteristics are very similar in the two regions. According with Nascimento [2005], a common feature of both American regions is the presence of low-level jets, SALLJ in South America and Great Plains low-level jet (GPLLJ) in North America. They transport low-level moisture from tropical and equatorial regions into the central U.S. and the Pampas, westerly bounded by the Rocky and Andes mountain chains, respectively, and may also get dynamically coupled to upperlevel jets, the polar jet in the Northern Hemisphere and the subtropical jet in the Southern Hemisphere, both mechanisms contributing to deep convection and severe storms in these regions (Figure 11).

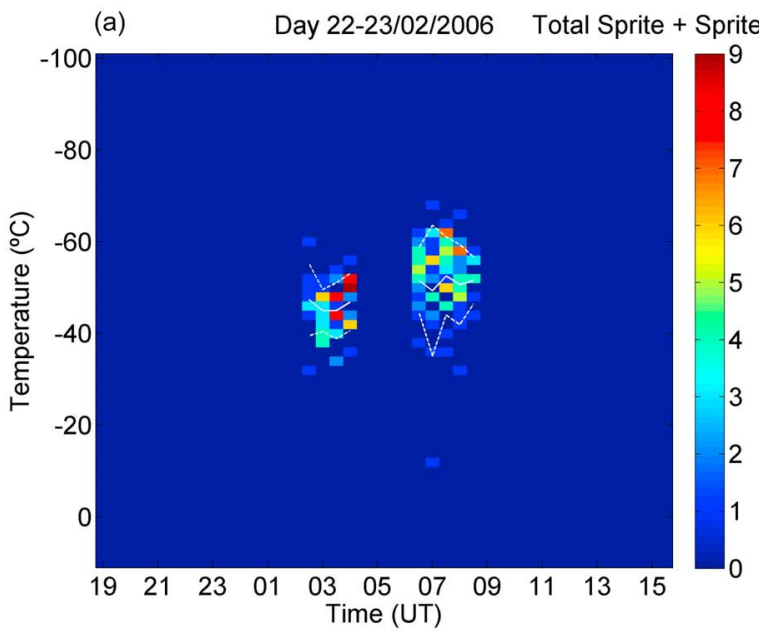

(b)

Day 22-23/02/2006 Total Halos

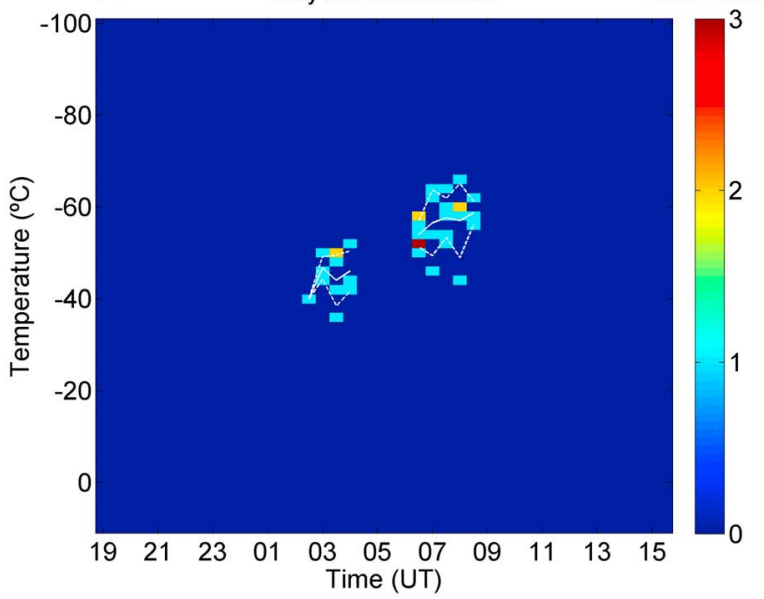

(c)

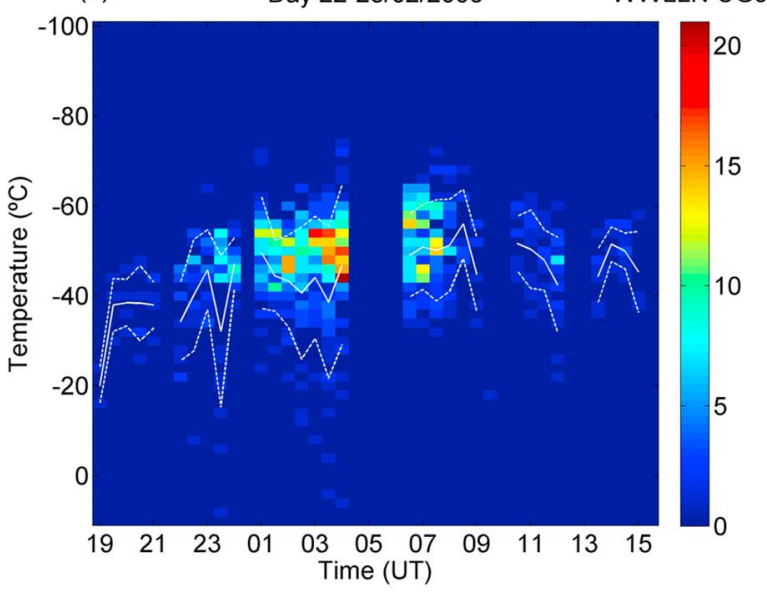

Figure 9. Time-temperature spectrograms of number of (a) sprites+sprite-halos, (b) halos, and (c) CGs detected by WWLLN. The spectrograms show the number of events (color scale) in $30 \mathrm{~min}$ intervals centered on the GOES IR satellite images and the average cloud top temperature with which they were associated (y axis) during the lifetime of the MCS (x axis). 

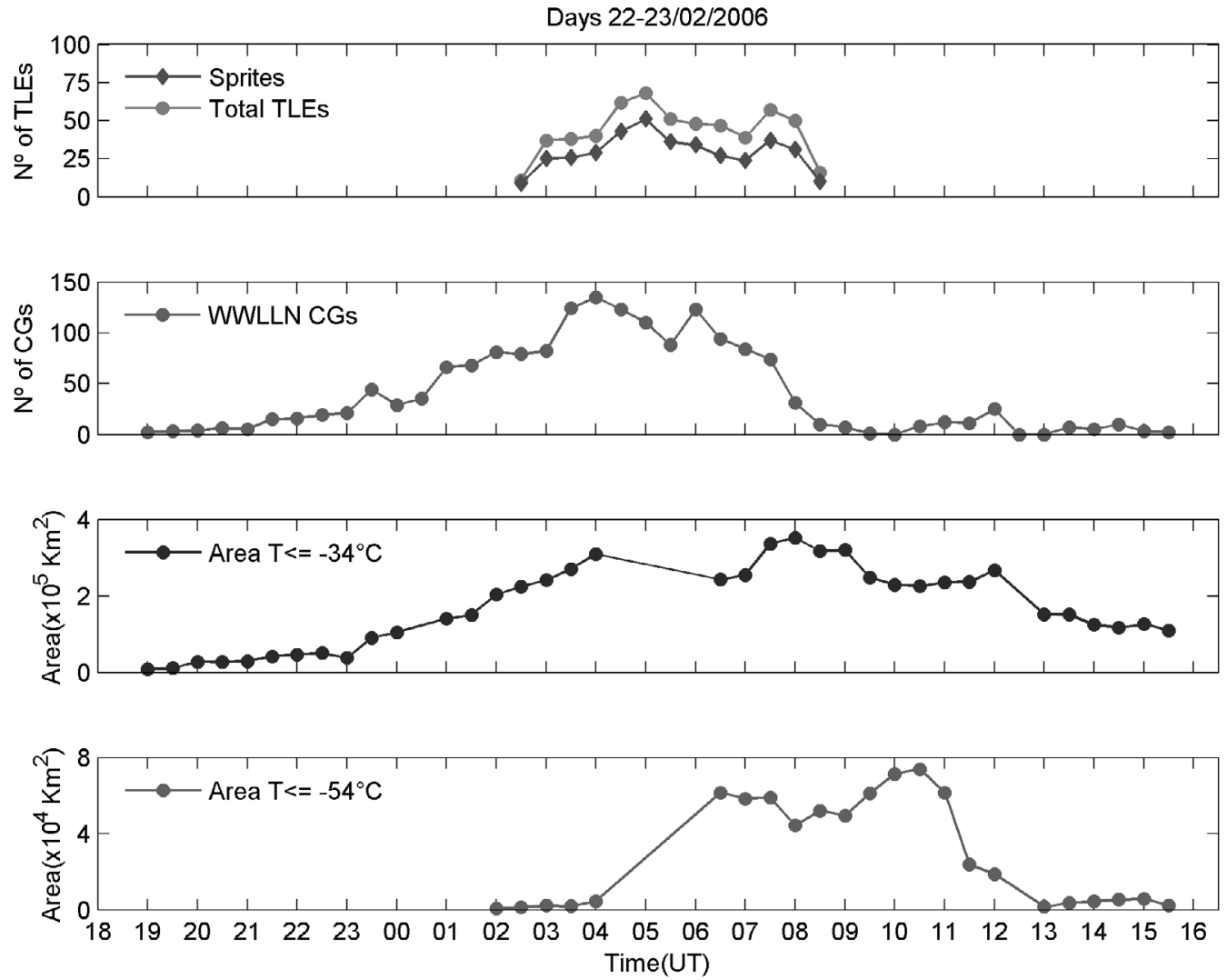

Figure 10. The first plot shows the temporal development of sprite and total TLE occurrence rates in 30 min intervals centered on the GOES IR satellite images. On the second plot is the WWLLN detected CG occurrence rates in 30 min intervals. The contiguous area of cloud cover with $\mathrm{T}_{\mathrm{c}}<-34^{\circ} \mathrm{C}$ (general cloud cover), and the area with $\mathrm{T}_{\mathrm{c}}<-54^{\circ} \mathrm{C}$ (convective cloud cover) are shown on the third and fourth plot, respectively.
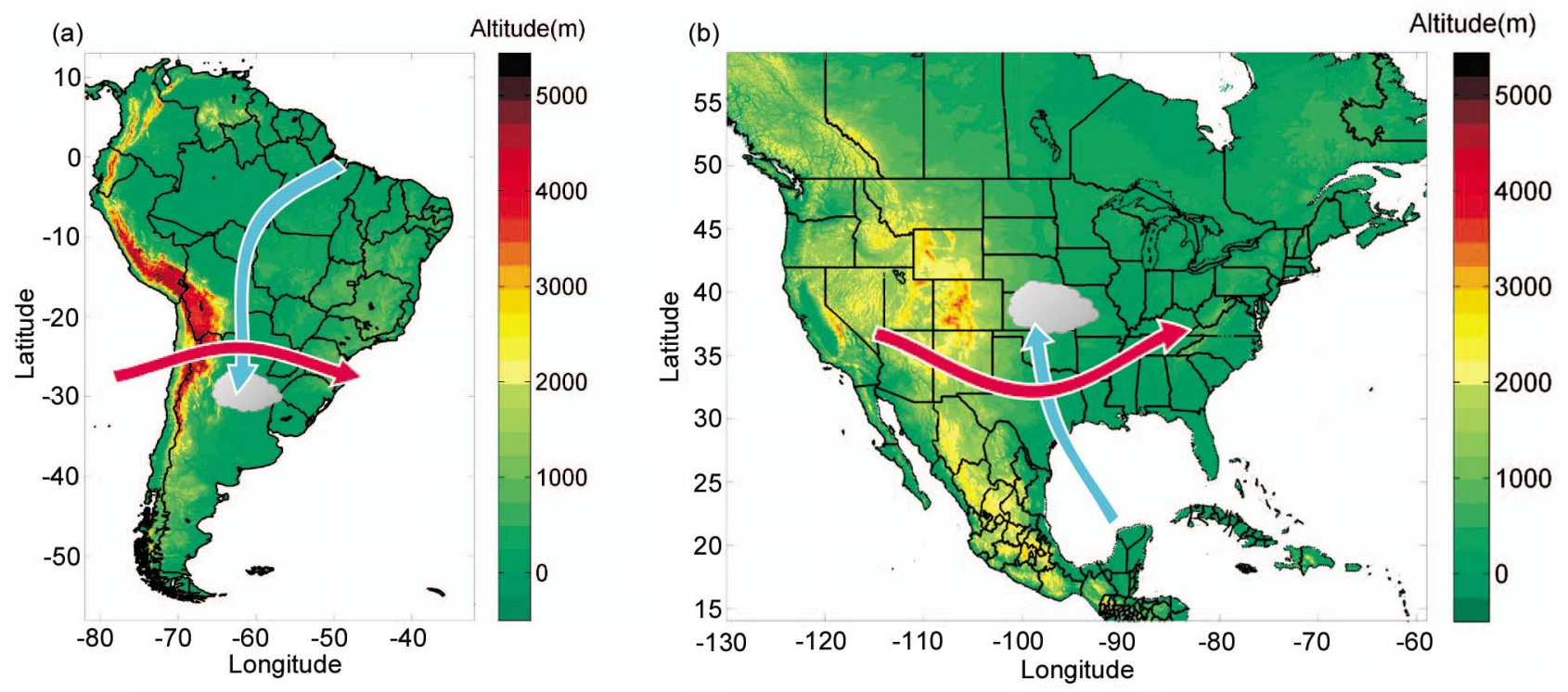

Figure 11. Illustrations showing low level jets, transporting moisture from the tropics into the continent, and upper level jets and their role in forcing formation of MCS in (a) central South America and (b) central North America. The colors represent the land altitude and show the Andes Mountains in South America, reaching $6962 \mathrm{~m}$, and the Rocky Mountains in the USA, reaching $4401 \mathrm{~m}$. 
[41] The main synoptic difference between South and North American TLE-producing MCSs is that in South America it is common for them to develop in the prefrontal region of cold fronts. This was the case of the Argentine storm that moved northeastward with a speed of $\sim 60 \mathrm{~km} / \mathrm{h}$ due to the northeastward motion of the cold front driving it. The frontal system was the forcing that was needed for convection to be initiated in that region, breaking the strong convection inhibition and overcoming the unfavorable thermodynamic conditions. The SALLJ provided the necessary "fuel," warm moist air, for the system to develop, and the Chaco Low combined with an upper tropospheric closed low over Argentina organized the flow/jet toward the Pampas. Strong advection of cold polar air into the region marked the end of its life cycle.

[42] Although the dynamics partly explain how this particularly prolific sprite-producing Argentine thunderstorm was formed, the fact that convection was not as deep as its North American counterparts prompted us to investigate other factors that may have influenced the system. Experimental evidence from TLE observations supports conventional breakdown as the dominant mechanism leading to sprite generation. The most well-accepted models involve the transport of large amounts of positive charges to the ground by cloud-to-ground lightning discharges generating quasielectrostatic fields that break down the air at mesospheric altitudes and produce enough ionization for the sprite streamers to develop [Pasko et al., 1997; São Sabbas, 2003]. The parameter related to the charge transferred to the ground to create sprites is the charge moment change, which is estimated from VLF/ELF measurements. Charge moment change thresholds for sprite production have been broadly studied; for example, Huang et al. [1999], found a minimum total charge moment change of $300 \mathrm{Ckm}$. Hu et al. [2002] showed that lightning charge moment change $<600 \mathrm{Ckm}$ in $6 \mathrm{~ms}$ generates sprites with a probability of $10 \%$. Later, Cummer and Lyons [2005] estimated charge moment change thresholds of 350 and $600 \mathrm{Ckm}$ for two observation nights.

[43] Assuming that the lowest threshold of $350 \mathrm{Ckm}$ was applicable for the Argentine thunderstorm and that the charges came from a $10 \mathrm{~km}$ altitude charge layer [Pasko et al., 1997], we can estimate that a lower charge threshold to generate a single sprite was $35 \mathrm{C}$, therefore the minimum amount of charge produced inside the clouds to generate all 383 observed sprites during the $\sim 6.2$ hours, not including the halos, was $13,405 \mathrm{C}$. Adopting a more realistic altitude of $5 \mathrm{~km}$ [Marshall et al., 2001] for the positive charge layers of this thunderstorm, given that the cloud tops where the sprite parent CGs occurred were at $11.7-13.2 \mathrm{~km}$, the lower estimate of the total charge necessary to generate the observed sprites doubles to $26,810 \mathrm{C}$, or approximately $4,300 \mathrm{C}$ per hour. The average TLE-producing thunderstorm, with 70 sprites, would need to have only $4,900 \mathrm{C}$, or $\sim 2,100 \mathrm{C} / \mathrm{h}$. Hence, large amounts of positive charges needed to be produced inside the Argentine thunderstorm during its lifetime for this system to generate +CGs strong enough to create breakdown in the upper atmosphere above the thunderstorm more than 300 times.

[44] The observed prolific TLE production demands an efficient electrification mechanism that would produce substantial positive charge. However, the fact that this storm did not exhibit particularly deep convection, since the cloud tops of the most active convective regions did not reach the tropopause, distinguishes this Argentine thunderstorm from those of previous studies. The cloud top temperatures and consequent altitude that the thundercloud tops reach convey important information about the convective structure of the thunderstorms, and are related to electrification processes. Ushio et al. [2001] found a relationship between lightning activity and storm height, due to the strong updrafts that drive the altitude of the cloud tops and are a key factor in producing strong electrification [Wang and Liao, 2006]. Strong updrafts are the agent that supports the large ice particles and supercooled water droplets that undergo the noninductive collisions necessary to generate charges inside the clouds, according to current theories of cloud electrification [Zipser and Lutz, 1994].

[45] One possible explanation may be related to a large aerosol concentration in the air masses from which the convective systems originated due to smoke from forest fires. Lyons et al. [1998] related the exceptional increase of sprite production by thunderstorms over the central United States during the northern hemisphere summer months of AprilJune 1998 due to ingestion of smoke from forest fires that were widespread in Mexico during the summer due to El Niño-related droughts. In the most interesting case cited, the percentage of + CGs increased up to $59 \%$ and $77 \%$ for convective storms within a frontal system that formed in the western edge of an air mass with $>150 \mu \mathrm{g} / \mathrm{m}^{3}$ concentration of aerosol particles with dimensions $<10 \mu \mathrm{m}\left(\mathrm{PM}_{10}\right)$. The effect of the aerosol particles in the $+\mathrm{CG}$ activity was consistent throughout the studied period: the number of flashes observed was similar to the previous 2 years with a $48 \%$ increase of $+\mathrm{CG}$ occurrence and a $12 \%$ increase in the average peak current. The consequence was an increase in the sprite production, with 380 sprites observed above the most prolific thunderstorm documented by the authors until 1998.

[46] February is an austral summer month and as such is part of the wet season, so forest fires are not expected to be significant at this time of the year in South America. However, fire count data from the AVHRR/NOAA12 satellite (http://sigma.cptec.inpe.br/queimadas) showed 200 fires burning savannah and pasture areas between the 20 and 22 February 2006 to the north of the MCS region. Figure 12 shows the emission source estimate of biomass burning aerosol with diameter $<2.5 \mu \mathrm{m}\left(\mathrm{PM}_{2.5}\right)$ in the period $20-22$ February 2006. The main sources of $\mathrm{PM}_{2.5}$ changing the atmospheric composition on the convective area were vegetation fires that took place over Paraguay and Argentina shown in Figure 12 as localized and intense emissions. The emission region is north of and relatively close to the convective initiation area such that the aerosols produced could be transported southward to the convective initiation region by the SALLJ (Figure 3b). Using the Coupled Aerosol-Tracer Transport model from the Brazilian developments on Regional Atmospheric Modeling System (CATT-BRAMS) [Freitas et al., 2005, 2009; Longo et al., 2010], we were able to estimate the aerosol mass concentration $\left(\mathrm{PM}_{2.5}\right)$ in the atmosphere taking into account the wind transport. CATTBRAMS is an online transport model fully consistent with the simulated atmospheric dynamics of the BRAMS regional numerical model. Emission sources from biomass burning and urban industrial vehicular activities for trace gases and 


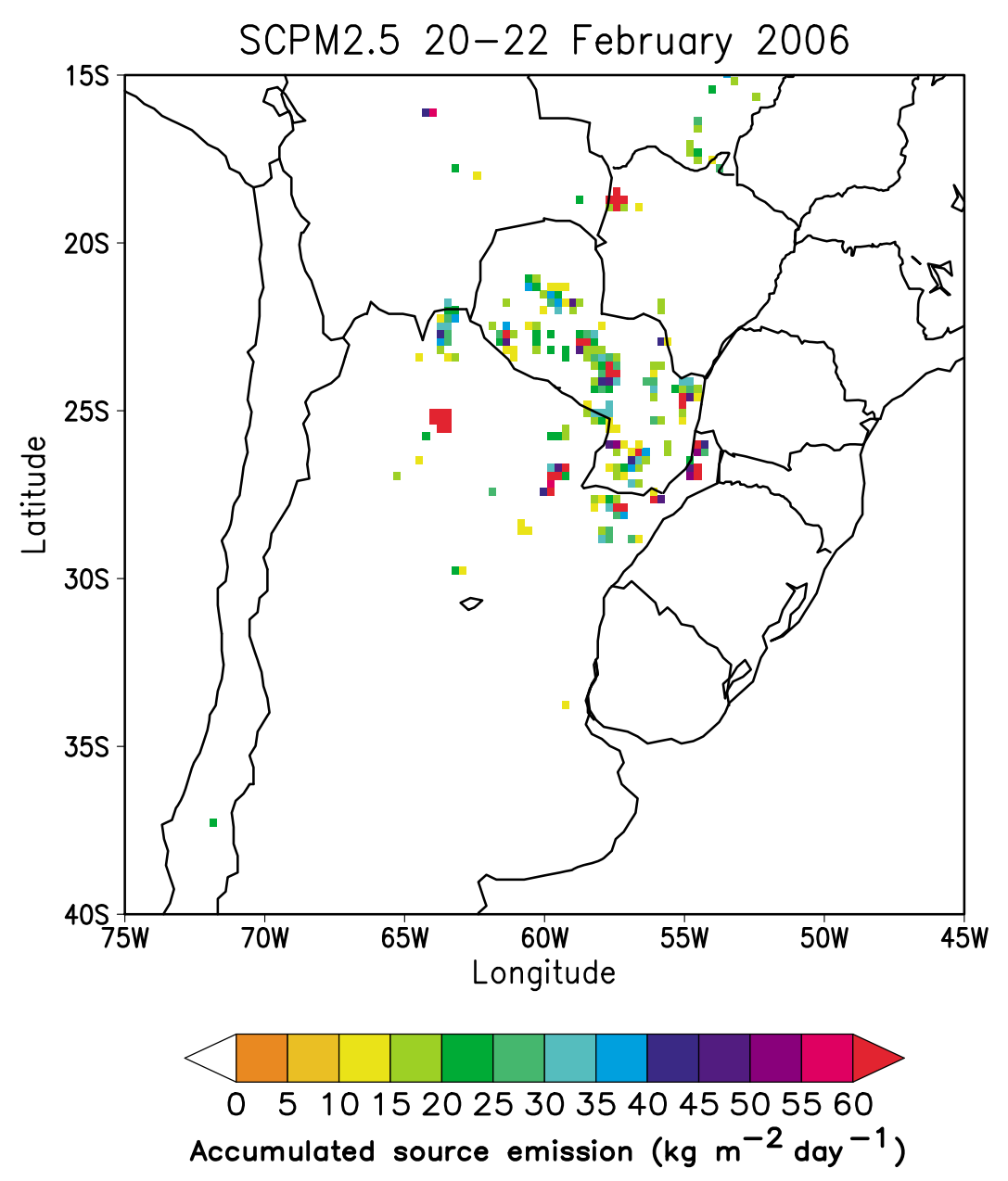

Figure 12. Accumulated forest fire source emissions from 20 February 20060000 UT to 22 February 2006 18:00 UT obtained from the AVHRR/NOAA12 satellite.

from biomass burning aerosol particles are obtained from several published data sets and remote sensing information. The tracer and aerosol mass concentration prognostics include the effects of subgrid scale turbulence in the planetary boundary layer, convective transport by shallow and deep moist convection, wet and dry deposition, and plume rise associated with vegetation fire atmospheric dynamics of the BRAMS regional numerical model.

[47] Figure 13a shows the column integrated $\mathrm{PM}_{2.5}$ concentration on 20 February 2006 at 2100 UTC, 20 hours prior to the first convective storm development. Figure $13 \mathrm{~b}$ shows the evolution of the concentration on 21 February 2006 at 2100 UTC with southern transport of the aerosols and increase in the concentration due to the new fires and continued activity of the previous sources. Figure $13 \mathrm{c}$ shows the air masses' aerosol concentrations on 22 February 2006 at 1800 UTC, 1 hour prior to the development of the first storms. The $\mathrm{PM}_{2.5}$ aerosols column integrated concentration reached $10,000 \mu \mathrm{g} / \mathrm{m}^{2}$ in the region where the convective activity initiated and $5,000 \mu \mathrm{g} / \mathrm{m}^{2}$ in the surrounding areas. Figure 13d, obtained on 23 February 2006 at 2100 UTC, shows the cleaner atmosphere after the thunderstorm has dissipated. The model simulation is corroborated by the MODIS (Moderate Resolution Imaging Spectroradiometer) retrieval of the aerosol optical depth (AOD) at $550 \mathrm{~nm}$ from the Aqua satellite [Remer et al., 2006]. For the time period above, the mean AOD at this channel over the convective area was $\sim 0.4$ (Figure 14).

[48] Lyons et al. [1998] and Fernandes et al. [2006] suggested that aerosols may affect lightning production in different ways. The three main responses are (1) the dramatic reduction of lightning activity near to cessation, (2) the increase of the total lightning rate independent of polarity, and (3) and the increase of discharges with positive polarity. Fernandes et al. [2006] also found an increase in the percentage of $+\mathrm{CGs}$ and in their peak current in thunderstorms over the Amazon Basin within $8-14^{\circ} \mathrm{S}$ and $59-66^{\circ} \mathrm{W}$ in South America associated with large column integrated concentrations of $\mathrm{PM}_{2.5}$ aerosols estimated using the CATT/BRAMS model [Freitas et al., 2009].

[49] Given the $10,000 \mu \mathrm{g} / \mathrm{m}^{2} \mathrm{PM}_{2.5}$ concentration estimated in the region where the TLE-producing MCS developed, we suggest that the presence of smoke from forest fires with large aerosol concentrations may have affected thunderstorm electrification to enhance the $+\mathrm{CG}$ production, similar to what was reported by Lyons et al. [1998] and Fernandes et al. [2006]. The smoke might have been a source of ice nuclei, influencing the production of ice particles that 
(a) PM2.5 20 February 2006, 21:00UTC
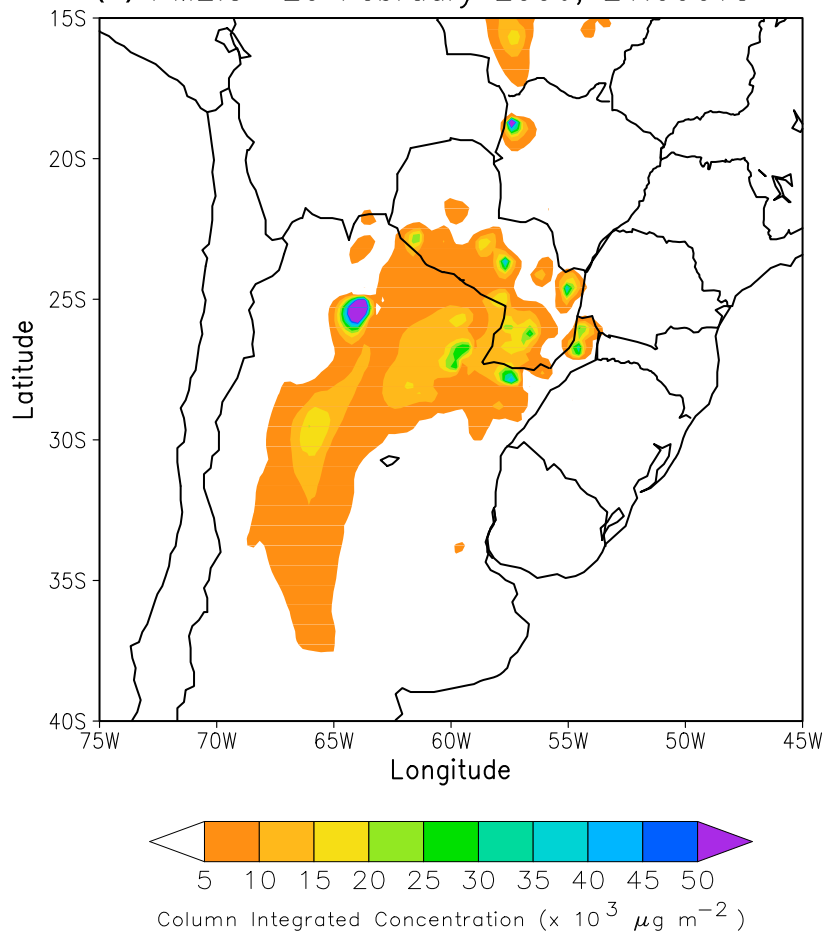

(c) PM2.5 22 February 2006, 18:00UTC

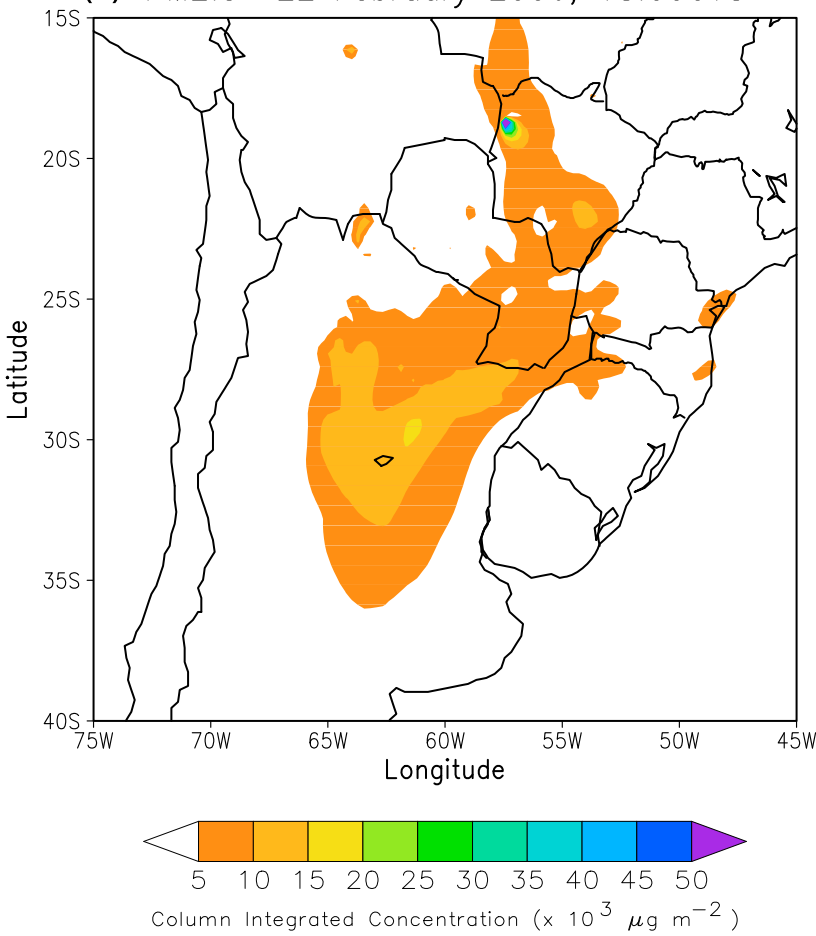

(b) PM2.5 21 February 2006, 21:00UTC
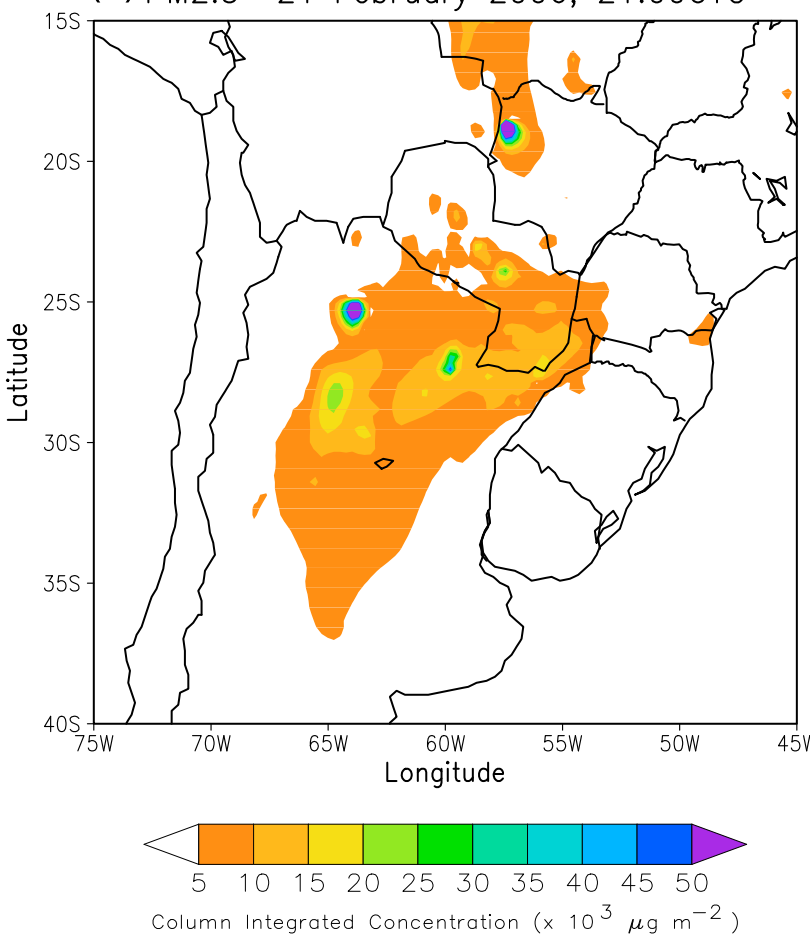

(d) PM2.5 23 February 2006, 21:00UTC

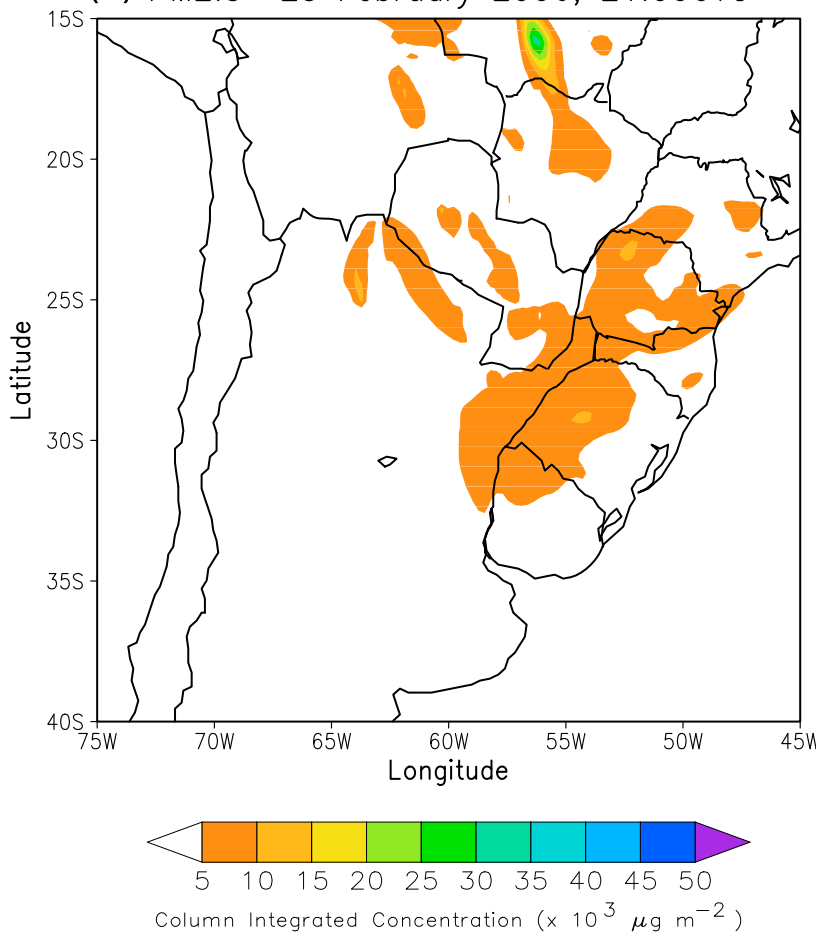

Figure 13. Spatial distribution of column integrated $\mathrm{PM}_{2.5}$ aerosols concentrations calculated by the CATT-BRAMS model. (a) 20 February 2006 at 21:00 UTC, 20 hours prior to the first convective storms development; (b) 21 February 2006 at 21:00 UTC; (c) 22 February 2006 at 18:00 UTC one hour prior to the development of the first storms; (d) 23 February 2006 at 21:00 UTC, shows the cleaner atmosphere after the MCS had dissipated. 


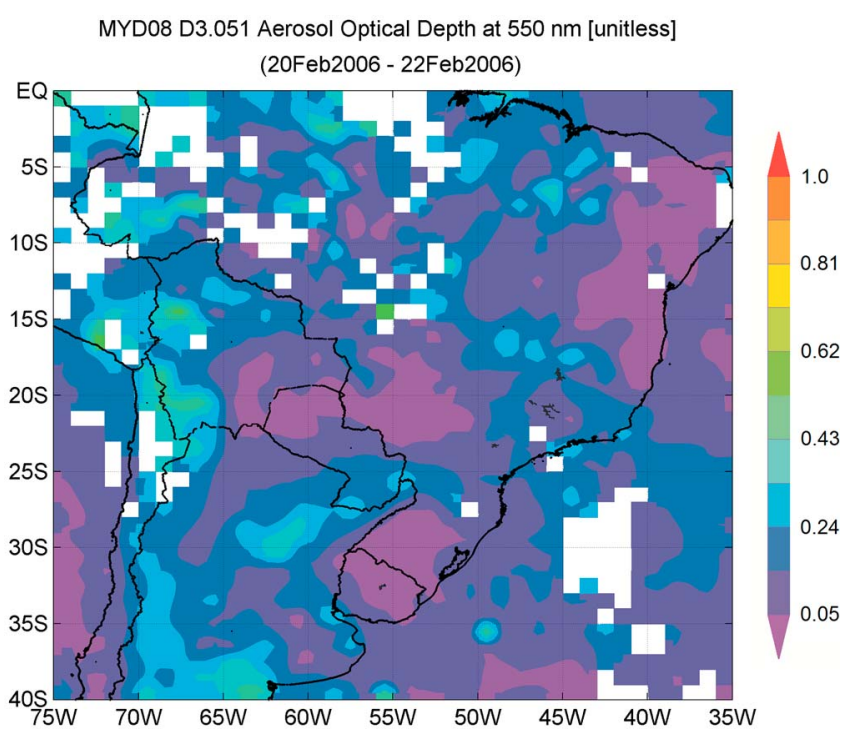

Figure 14. Average aerosol optical depth (AOD) at $550 \mathrm{~nm}$ between 20-22 February 2006 retrieved from MODIS onboard Aqua satellite.

get positively charged, since the TMI/TRMM measured a low minimum brightness temperature of $84 \mathrm{~K}$ for the small convective core of one of the convective systems that evolved into the TLE-producing MCS. In accord with Zipser et al. [2006], low TMI/TRMM brightness temperatures indicate high concentrations of precipitating ice. The $84 \mathrm{~K}$ is within the lowest values reported by Zipser et al. [2006] in their severe storm global distribution, so at the early stages of its development the TLE-producing thunderstorm may already have had a high density of ice particles, which are important for cloud electrification processes [Ushio et al., 2001; Wang and Liao, 2006; Zipser and Lutz, 1994]. Petters et al. [2009] generated smoke in a Colorado State University continuous flow diffusion chamber through controlled burns of 21 biomass fuels from the United States and Asia and tested the ability of smoke particles to nucleate ice as condensation/ immersion freezing nuclei at $30{ }^{\circ} \mathrm{C}$. They found that smoke from 9 of the 21 fuels acted as ice nuclei at fractions of $1: 10,000$ to $1: 100$ particles in at least one burn of each fuel. Statistically, fuels associated with low organic carbon fraction, high water-soluble ion content, and a more flaming fire phase appeared to be more efficient ice nuclei. Using a bottom-up emission model, Petters et al. [2009] estimated that smoke that emits ice nuclei fractions exceeding 1:10,000 particles can perturb ice nuclei concentrations on a regional scale.

[50] Biomass burning emissions (gases and aerosols) may have an impact on several scales with the long-range transport by synoptical systems [Freitas et al., 2005] changing the chemistry composition of the atmosphere over areas much larger than the region where the fires took place [e.g., Prins et al., 1998]. Besides the contribution of greenhouse gases to global warming, smoke aerosols have an impact on the radiative budget and cloud microphysics [Kaufman, 1995; Rosenfeld, 1999; Andreae et al., 2004; Koren et al., 2004] affecting the hydrologic cycle and boundary layer properties [Longo et al., 2006]. In addition, smoke aerosols as well as ozone formation by biomass burning emission precursors are observed to frequently make the air quality of the neighbor areas even worse than for the South American megacities [Ignotti et al., 2010].

\section{Conclusions}

[51] The conclusions of this work may be summarized as follows:

[52] 1. A detailed analysis was performed of the relationship between TLE locations and the convective characteristics of the underlying MCS for an unusually prolific sprite-producing mesoscale convective system over northern Argentina. Observations made from Brazil on 2223 February 2006 over a $\sim 6.2$ hours interval recorded a total of 444 TLEs, of which 383 were sprites.

[53] 2. The TLE-producing thunderstorm became a MCS between 9.5 and 11.5 hours after the first convective storms from which it originated had developed. The system had a minimum lifetime of 20 hours, 8.5 of those hours as an MCS, and its maximum extent was $\sim 430,000 \mathrm{~km}^{2}$. This MCS had a multicellular structure with 19 convective regions identified and tracked. Their estimated areas ranged between $\sim 77 \mathrm{~km}^{2}$ and $\sim 57,773 \mathrm{~km}^{2}$ during maximum extent, and their durations ranged from $\sim 30 \mathrm{~min}$ to $\sim 8.5$ hours, respectively. Gust winds of $\sim 39-50 \mathrm{~km} / \mathrm{h}$ were associated with this thunderstorm.

[54] 3. TLEs occurred above the "individual stratiform regions" formed around these convective areas, associated with cloud top temperatures varying from $-45^{\circ} \mathrm{C}$ to $-53{ }^{\circ} \mathrm{C}$ (corresponding altitudes $11.7-13.2 \mathrm{~km}$, respectively) from the beginning to the end of the night. Similarly, WWLLN detected CGs were associated with cloud top regions varying from $-20{ }^{\circ} \mathrm{C}$ to $-50{ }^{\circ} \mathrm{C}(7.5-13.3 \mathrm{~km}$, respectively). These cloud top temperatures associated with TLEs were significantly warmer by $\sim 10-20^{\circ} \mathrm{C}$ than those reported for similarly large TLE-producing system in the United States.

[55] 4. The minimum temperature that the convective cores reached varied between $-60{ }^{\circ} \mathrm{C}$ and $-74{ }^{\circ} \mathrm{C}$, with corresponding altitudes of $\sim 14.0 \mathrm{~km}$ and $\sim 16.7 \mathrm{~km}$, respectively. None of them reached the tropopause, at $\sim 17.1 \mathrm{~km}$; hence, the MCS convective activity was not as deep as usually observed in other TLE-producing MCS whose convective cores generally reach and often overshoot the tropopause. The overall cloud top temperatures of these thunderstorms was $\sim 10-20^{\circ} \mathrm{C}$ warmer than central United States TLE-producing MCSs and other TLE-producing thunderstorms in South America.

[56] 5. A lower hourly charge transfer rate threshold of $\sim 4,300 \mathrm{C} / \mathrm{h}$ to originate the observed 383 total sprite production was estimated on the basis of a lower charge moment change threshold of $350 \mathrm{Ckm}$, reported in the literature, and a $5 \mathrm{~km}$ altitude charge removal altitude estimated for the Argentine storm. This rate is twice the rate estimated for an average TLE-producing MCS, reported in the literature to produce 70 sprites.

[57] 6. TMI/TRMM data for the early development stage of one of the convective systems that evolved into the TLEproducing MCS showed a low brightness temperature of $84 \mathrm{~K}$ for its small convective core, indicative of significant ice content, which is important for cloud electrification processes.

[58] 7. It is suggested that the unusually high incidence of TLEs in what was otherwise only a moderately convective 
MCS may be related to the influence on the electrification process of smoke from forest fires in Paraguay and northern Argentina, similarly to what has been previously proposed in the literature. It is also suggested that the smoke from biomass burning may have been a source of ice nuclei affecting the production of ice particles that get positively charged, accounting for the charge transfer rate necessary to originate the observed TLE production.

[59] Finally, the differences and similarities between this prolific TLE-producing system in Argentina and other TLE-producing systems over the United States discussed in this work help to identify the key convective characteristics for TLE-producing thunderstorms. In particular, it may be useful for forecasting TLE occurrences anywhere around the globe solely on the basis of space-based platform data sets.

[60] Acknowledgments. We thank CPTEC for providing the GOES IR imagery used. Special thanks go to M. Botino for useful discussions about the data format and conversion techniques, and to W. Anabor, E. Dal Piva, C. A. Morales Rodriguez, R. Porfirio Rocha, V. da Silva Júnior, and M. A. Gan for useful input about the meteorological aspects of the analysis. Thanks go to J. G. Martins dos Santos for running the CATT-BRAMS model and making the figures, and to J. R. Rozante for providing the NCEP analysis data. Thanks go to D. D. Sentman for useful discussions that contributed to several aspects of this work and also to C. L. da Silva. We thank the World Wide Lightning Location Network (http://wwlln.net), a collaboration among over 40 universities and institutions, for providing the lightning location data used in this paper. This work was developed with the support of FAPESP DEELUMINOS grant $04 / 12350-7$, and partially supported by FAPESP grant 02/01329-1 and U.S. National Science Foundation under grants ATM0091825 and ATM-0355190 to the University of Washington. J. N. Thomas was partially supported by the U.S. Geological Survey Mendenhall Postdoctoral Fellowship Program.

[61] Philippa Browning thanks Hiroshi Fukunishi and another reviewer for their assistance in evaluating this paper.

\section{References}

Anabor, V., D. J. Stensrud, and O. L. L. de Moraes (2008), Serial upstream-propagating mesoscale convective system events over southeastern South America, Mon. Weather Rev., 136, 3087-3105, doi:10.1175/2007MWR2334.1.

Andreae, M., D. Rosenfeld, P. Artaxo, A. Costa, G. Frank, K. M. Longo, and M. A. F. Silva Dias (2004), Smoking rain clouds over the Amazon, Science, 303, 1342-1345, doi:10.1126/science.1092779.

Barrington-Leigh, C. P., U. S. Inan, and M. Stanley (2001), Identification of sprites and elves with intensified video and broadband array photometry, J. Geophys. Res., 106(A2), 1741-1750, doi:10.1029/ 2001JA900117.

Boccipio, D. J., E. R. Williams, S. J. Heckman, W. A. Lyons, I. T. Baker, and R. Boldi (1995), Sprites, ELF transients, and positive ground strokes, Science, 269, 1088, doi:10.1126/science.269.5227.1088.

Brooks, H. E., J. W. Lee, and J. P. Craven (2003), The spatial distribution of severe thunderstorm and tornado environments from global reanalysis data, Atmos. Res., 67-68, 73-94, doi:10.1016/S0169-8095(03)00045-0.

Chen, A. B., et al. (2008), Global distributions and occurrence rates of transient luminous events, J. Geophys. Res., 113, A08306, doi:10.1029/ 2008JA013101.

Cummer, S. A., and W. A. Lyons (2005), Implications of lightning charge moment changes for sprite initiation, J. Geophys. Res., 110, A04304, doi:10.1029/2004JA010812.

Durkee, J. D., and T. L. Mote (2010), A climatology of warm-season mesoscale convective complexes in subtropical South America, Int. J. Climatol., 30(3), 418-431, doi:10.1002/joc.1893.

Fernandes, W. A., I. R. C. A. Pinto, O. Pinto Jr., K. M. Longo, and S. R. Freitas (2006), New findings about the influence of smoke from fires on the cloud-to-ground lightning characteristics in the Amazon region, Geophys. Res. Lett., 33, L20810, doi:10.1029/2006GL027744.

Figueroa, S. N., P. Satyamurty, and P. L. S. Dias (1995), Simulations of the summer circulation over the South American region with an Eta coordinate model, J. Atmos. Sci., 52, 1573-1584, doi:10.1175/1520-0469 (1995)052.
Franz, R. C., R. J. Nemzek, and J. R. Winckler (1990), Television image of a large upward electrical discharge above a thunderstorm system, Science, 249, 48-51, doi:10.1126/science.249.4964.48.

Freitas, S., K. Longo, M. Silva Dias, P. Silva Dias, R. Chatfield, E. Prins, P. Artaxo, G. Grell, and F. Recuero (2005), Monitoring the transport of biomass burning emissions in South America, Env. Fluid Mech., 5(1-2), 135-167, doi:10.1007/s10652-005-0243-7.

Freitas, S. R., et al. (2009), The coupled aerosol and tracer transport model to the Brazilian developments on the Regional Atmospheric Modeling System (CATT-BRAMS) Part 1: Model description and evaluation, Atmos. Chem. Phys., 9, 2843-2861.

Fukunishi, H., Y. Takahashi, T. Adachi, and R. Miyasato (2001), Characteristics of sprites and elves observed in winter above Japan, in Proceedings of IAGA-IASEI Joint Scientific Assembly, p. 98, Hanoi, Vietnam.

Gandu, A. W., and P. L. S. Dias (1998), Impact of tropical heat sources on the South American tropospheric upper circulation and subsidence, J. Geophys. Res., 103, 6001-6015, doi:10.1029/97JD03114.

Gerken, E. A., U. S. Inan, and C. P. Barrington-Leigh (2000), Telescopic imaging of sprites, Geophys. Res. Lett., 27(17), 2637-2640, doi:10.1029/ 2000GL000035

Hampton, D. L., M. J. Heavner, E. M. Wescott, and D. D. Sentman (1996), Optical spectral characteristics of sprites, Geophys. Res. Lett., 23(1), 89-92, doi:10.1029/95GL03587.

Houze, R. A., Jr. (2004), Mesoscale convective systems, Rev. Geophys., 42, RG4003, doi:10.1029/2004RG000150.

Huang, E., E. Williams, R. Boldi, S. Heckman, W. Lyons, M. Taylor, T. Nelson, and C. Wong (1999), Criteria for sprites and elves based on Schumann resonance observations, J. Geophys. Res., 104(D14), 16,943-16,964, doi:10.1029/1999JD900139.

Hu, W., S. A. Cummer, W. A. Lyons, and T. E. Nelson (2002), Lightning charge moment changes for the initiation of sprites, Geophys. Res. Lett., 29(22), 2053, doi:10.1029/2001GL014293.

Ignotti, E., J. Valente, K. M. Longo, S. R. Freitas, S. Hacon, and P. Artaxo (2010), Impact on human health of particulate matter emitted from burnings in the Brazilian Amazon region, Rev. Saúde Pública, 44, 121-130. Inan, U. S., C. Barrington-Leigh, S. Hansen, V. S. Glukhov, T. F. Bell, and R. Rairden (1997), Rapid lateral expansion of optical luminosity in lightning-induced ionospheric flashes referred to as "elves", Geophys. Res. Lett., 24, 583-586.

Jacobson, A. R., R. Holzworth, and J. Harlin (2006), Performance acessment assessment of the World Wide Lightning Location Network (WWLLN), using the Los Alamos Sferic Array (LASA) and Ground Truth, J. Atmos. Oceanic Tech., 23, 1082, doi:10.1175/JTECH1902.1.

Kalnay, E., et al. (1996), The NCEP/NCAR 40-year Reanalysis Project, Bull. Am. Meteor. Soc., 77, 437-471, doi:10.1175/1520-0477(1996)077.

Kaufman, Y. J. (1995) Remote sensing of direct and indirect aerosol forcing, in Aerosol Forcing of Climate: Report of the Dahlem Workshop on Aerosol Forcing of Climate, edited by R. J. Charlson and J. Heintzenberg, John Wiley, Chichester, U. K.

Koren, I., Y. Kaufman, L. A. Remer, and J. V. Martins (2004), Measurement of the effect of Amazon smoke on inhibition of cloud formation, Science, 303, 1342-1345, doi:10.1126/science.1089424.

Kummerow, C. W., T. Barnes, T. Kozu, J. Shiue, and J. Simpson (1998), The Tropical Rainfall Measuring Mission (TRMM) sensor package, J. Atmos. Oceanic Technol., 15, 809-817, doi:10.1175/1520-0426 (1998)015<0809:TTRMMT>2.0.CO;2.

Li, J., S. A. Cummer, W. A. Lyons, and T. E. Nelson (2008), Coordinated analysis of delayed sprites with high-speed images and remote electromagnetic fields, J. Geophys. Res., 113, D20206, doi:10.1029/ 2008JD010008.

Liu, N., and V. P. Pasko (2004), Effects of photoionization on propagation and branching of positive and negative streamers in sprites, J. Geophys. Res., 109, A04301, doi:10.1029/2003JA010064.

Longo, K. M., S. R. Freitas, M. A. F. Silva Dias, and P. Silva Dias (2006), Numerical modelling of the biomass-burning aerosol direct radiative effects on the thermodynamics structure of the atmosphere and convective precipitation, in International Conference on Southern Hemisphere Meteorology and Oceanography, vol. 8, pp. 121-129, INPE, São José dos Campos, Brazil.

Longo, K. M., S. R. Freitas, M. O. Andreae, A. Setzer, E. Prins, and P. Artaxo (2010), The Coupled Aerosol and Tracer Transport model to the Brazilian developments on the Regional Atmospheric Modeling System (CATTBRAMS) Part 2: Model sensitivity to the biomass burning inventories, Atmos. Chem. Phys., 10, 5785-5795.

Lyons, W. A. (1996), Sprite observations above the U.S. High Plains in relation to their parent thunderstorm systems, J. Geophys. Res., 101, 29,641-29,652, doi:10.1029/96JD01866. 
Lyons, W. A., T. E. Nelson, E. R. Williams, J. A. Cramer, and T. R. Turner (1998), Enhanced Positive cloud-to-ground lightning in thunderstorms ingesting smoke from fires, Science, 282, 5386, doi:10.1126/science.282. 5386.77

Lyons, W. A., L. M. Andersen, and T. E. Nelson (2006), Characteristics of sprite-producing electrical storms in the STEPS 2000 domain, Preprints, in Second Conf. on Meteorological Applications of Lightning Data, Amer. Meteor. Soc., Atlanta, Georgia.

Luque, A., and U. Ebert (2009) Emergence of sprite streamers from screening-ionization waves in the lower ionosphere, Nat. Geosci., 2 , 757-760, doi:10.1038/NGEO662.

Maddox, R. A. (1980), Mesoscale convective complexes, Bull. Am. Meteorol. Soc., 61, 1374-1387.

Marengo, J. A., and C. Nobre (2009), Clima da Região Amazônica, in Tempo e Clima no Brasil, edited by I. F. A. Cavalcanti, N. J. Ferreira, M. G. A. J. da Silva, and M. A. F. Silva Dias, pp. 197-212, Oficina de Textos, São Paulo, Brazil.

Marengo, J. A., M. W. Douglas, and P. L. Silva Dias (2002) The South American low level jet east of the Andes during the 1999 LBATRMM and LBA-WET AMC campaign, J. Geophys. Res., 107(D20), 8079, doi:10.1029/2001JD001188.

Marshall, T. C., M. Stolzenburg, W. D. Rust, E. R. Williams, and R. Boldi (2001), Positive charge in the stratiform cloud of a mesoscale convective system, J. Geophys. Res., 106, 1157-1163, doi:10.1029/2000JD900625.

Miyasato, R., M. J. Taylor, H. Fukunishi, and H. C. Stenbaek-Nielsen (2002), Statistical characteristics of sprite halo events using coinciden photometric and imaging data, Geophys. Res. Lett., 29(21), 2033 doi:10.1029/2001GL014480.

Nascimento, E. L. (2005), Previsão de tempestades severas utilizando-se parâmetros convectivos e modelos de mesoescala: uma estratégia operacional adotável no Brasil?, Rev. Brasileira Meteorol., 20(1), 121-140.

Nesbitt, S. W., E. J. Zipser, and D. J. Cecil (2000), A census of precipitation features in the Tropics using TRMM: Radar, ice scattering, and ice observations, J. Clim., 13, 4087-4106, doi:10.1175/1520-0442 (2000)013.

Neubert, T., T. H. Allin, H. Stenbaek-Nielsen, and E. Blanc (2001), Sprites over Europe, Geophys. Res. Lett., 28, 3585-3588, doi:10.1029/ $2001 \mathrm{GL} 013427$.

Orlanski, I. (1975) A rational subdivision of scales for atmospheric process, Bull. Am. Meteor. Soc., 56, 527-530.

Parker, M. D., and R. H. Johnson (2000), Organizational modes of midlatitude mesoscale convective systems, Mon. Weather Rev., 128, 34133436, doi:10.1175/1520-0493(2001)129.

Pasko, V. P., U. S. Inan, and T. F. Bell (1997), Sprites produced by quasielectrostatic heating and ionization in the lower ionosphere, J. Geophys. Res., 102, 4529-4561, doi:10.1029/96JA03528.

Pasko, V. P., U. S. Inan, and T. F. Bell (1998), Spatial structure of sprites, Geophys. Res. Lett., 25(12), 2123-2126.

Pasko, V. P., M. A. Stanley, J. D. Mathews, U. S. Inan, and T. G. Wood (2002), Electrical discharge from a thundercloud top to the lower ionosphere, Nature, 416, 152, doi:10.1038/416152a.

Petters, M. D., et al. (2009), Ice nuclei emissions from biomass burning, J. Geophys. Res., 114, D07209, doi:10.1029/2008JD011532.

Pinto, O., Jr., M. M. F. Saba, I. R. C. A. Pinto, F. T. São Sabbas, K. P. Naccarato, M. J. Taylor, P. D. Pautet, and R. H. Holzworth (2004), Thunderstorm and lightning characteristics associated with sprites in Brazil, Geophys. Res. Lett., 31, L13103, doi:10.1029/2004GL020264.

Prins, E., J. Feltz, W. Menzel, and D. Ward (1998), An overview of GOES-8 diurnal fire and smoke results for SCAR-B and 1995 fire season in South America, J. Geophys. Res., 103(D24), 31,821-31,835, doi:10.1029/98JD01720.

Raizer, Yu. P., G. M. Milikh, M. N. Shneider, and S. V. Novakovsk (1998), Long streamers in the upper atmosphere above a thundercloud, J. Phys. D: Appl. Phys., 31, 3255-3264.

Remer, L. A., D. Ranré, Y. Kaufman, R. Levy, and S. Matoo (2006), Algorithm for remote sensing of tropospheric aerosol from MODIS: collection 005: The theoretical basis document, report, Modis Atmos., NASA, Washington, D. C. (Available at http://modis-atmos.gsfc.nasa.gov/ reference atbd.php.)

Rodger, C. J., J. B. Brundell, and R. L. Dowden (2005), Location accuracy of VLF World Wide Lightning Location (WWLL) network: Postalgorithm upgrade, Ann. Geophys., 23, 277-290.

Rosenfeld, D. (1999), TRMM observed first direct evidence of smoke from forest fires inhibiting rainfall, Geophys. Res. Lett., 26(20), 3101, doi:10.1029/1999GL006066.

Salio, P., M. Nicolini, and E. J. Zipser (2007), Mesoscale convective systems over southeastern South America and their relationship with the South American low-level jet, Mon. Weather Rev., 135, 1290 1309, doi:10.1175/MWR3305.1.
São Sabbas, F. T. (2003), Role of conductivity spatial structure in determining the locations of sprite initiation, $\mathrm{PhD}$ dissertation, Univ. of Alaska Fairbanks, Fairbanks, Alaska

São Sabbas, F. T., and D. D. Sentman (2003), Dynamical relationship of infrared cloud top temperatures with occurrence rates of cloud-to-ground lightning and sprites, Geophys. Res. Lett., 30(5), 1236, doi:10.1029/ 2002GL015382.

São Sabbas, F. T., D. D. Sentman, E. M. Wescott, O. Pinto Jr., O. Mendes Jr., and M. J. Taylor (2003), Statistical analysis of space-time relationships between sprites and lightning, J. Atmos. Sol. Terr. Phys., 65, 525-535, doi:10.1016/S1364-6826(02)00326-7.

São Sabbas, F., V. T. Rampinelli, J. Santiago, P. Stamus, S. L. Vadas, D. C. Fritts, M. J. Taylor, P. D. Pautet, G. D. Neto, and O. Pinto Jr. (2009), Characteristics of sprite and gravity wave convective sources present in satellite IR images during the SpreadFEx 2005, Brazil. Ann. Geophys., 27, 1279-1293.

Sato, M., and H. Fukunishi (2003), Global sprite occurrence locations and rates derived from triangulation of transient Schumann resonance events, Geophys. Res. Lett., 30(16), 1859, doi:10.1029/2003GL017291.

Sentman, D. D., E. M. Wescott, D. L. Osborne, D. L. Hampton, and M. J. Heavner (1995), Preliminary results from the Sprites 94 aircraft campaign: 1. Red Sprites, Geophys. Res. Lett., 22, 1205-1208, doi:10.1029/ 95GL00583.

Silva Dias, M. A. F., J. R. Rozante, and L. A. T. Machado (2009), Complexos Convectivos de Mesoescala na América do Sul, in Tempo e Clima no Brasil, edited by I. F. A. Cavalcanti et al., pp. 181-194, Oficina de Textos, São Paulo, Brazil.

Soula, S., O. van der Velde, J. Montanyà, T. Neubert, O. Chanrion, and M. Ganot (2009), Analysis of thunderstorm and lightning activity associated with sprites observed during the EuroSprite campaigns: Two case studies, Atmos. Res., 91, 514-528, doi:10.1016/j.atmosres.2008.06.017.

Stenbaek-Nielsen, H. C., D. R. Moudry, E. M. Wescott, D. D. Sentman, and F. T. São Sabbas (2000), Sprites and possible mesospheric effects, Geophys. Res. Lett., 27(23), 3829-3932, doi:10.1029/2000GL003827.

Su, H. T., R. R. Hsu, A. B. Chen, Y. J. Lee, and L C. Lee (2002), Observations of sprites over the Asian continent and over oceans around Taiwan, Geophys. Res. Lett., 29(4), 1044, doi:10.1029/2001GL013737.

Takahashi, T. (1978), Riming electrification as a charge generation mechanism in thunderstorms. J. Atmos. Sci., 35, 1536-1548, doi:10.1175/ 1520-0469(1978)035.

Taylor, M. J., L. C. Gardner, and C. Siefring (2000), Image Measurements During the 1999 Leonids-MAC Airborne Campaign: High-Resolution Meteor Ablation Signatures and Longitudinal Gravity Wave Study, in 2nd Leonids-MAC workshop, Tel Aviv, Israel.

Taylor, M. J., et al. (2008), Rare measurements of a sprite with halo event driven by a negative lightning discharge over Argentina, Geophys. Res. Lett., 35, L14812, doi:10.1029/2008GL033984.

Thomas, J., et al. (2007), A very active sprite-producing storm observed over Argentina, Eos Trans. AGU, 88(10), 117, doi:10.1029/ 2007EO100001.

Ushio, T., S. Heckman, D. Boccippio, H. Christian, and Z. I. Kawasaki (2001), A survey of thunderstorm flash rates compared to cloud top height using TRMM satellite data, J. Geophys. Res., 106(D20), doi:10.1029/2001JD900233.

Velasco, I., and J. M. Fritsch (1987), Mesoscale convective complexes in the Americas, J. Geophys. Res., 92, 9591-9613, doi:10.1029/ JD092iD08p09591.

Virji, H. (1981), A preliminary-study of summertime tropospheric circulation patterns over South-America estimated from cloud winds, Mon Weather Rev., 109, 599-610, doi:10.1175/1520-0493(1981)109.

Wang, K. Y., and S. A. Liao (2006), Lightning, radar reflectivity, infrared brightness temperature, and surface rainfall during the 2-4 July 2004 severe convective system over Taiwan area, J. Geophys. Res., 111, D05206, doi:10.1029/2005JD006411.

Wescott, E. M., H. C. Stenbaek-Nielsen, D. D. Sentman, M. J. Heavner, D. R. Moudry, and F. T. São Sabbas (2001), Triangulation of sprites, associated halos and their possible relation to causative lightning and micro-meteors, J. Geophys. Res., 106(A6), 10,467-10,477, doi:10.1029/2000JA000429.

Zipser, E. J., and K. R. Lutz (1994), The vertical profile of radar reflectivity of convective cells: A strong indicator of storm intensity and lightning probability?, Mon. Weather Rev., 122, 1751-1759.

Zipser, E. J., D. J. Cecil, C. Liu, S. W. Nesbitt, and D. P. Yorty (2006) Where are the most intense thunderstorms on Earth?, Bull. Am. Meteor. Soc., 87, 1057-1071, doi:10.1175/BAMS-87-8-1057.

R. R. Azambuja, J. C. Conforte, N. J. Ferreira, S. R. Freitas, O. Pinto, J. P. C. Santiago, and F. T. São Sabbas, Instituto Nacional de Pesquisas 
Espaciais, Sao José dos Campos, SP 12227-010, Brazil. (fernandasaosabbas@ gmail.com)

M. Bailey, P.-D. Pautet, and M. J. Taylor, Center for Atmospheric and Space Sciences, Utah State University, 4405 Old Main Hill, Logan, UT 84322, USA.

S. Cummer, Electrical and Computer Engineering Department, Duke University, Durham, NC 27708, USA.
N. J. Schuch, Southern Regional Space Research Center, CRS, INPEMCT, Santa Maria, RS 97105-900, Brazil.

N. N. Solorzano and J. N. Thomas, Department of Electrical and Computer Engineering, Digipen Institute of Technology, Redmond, WA 98052, USA. 